TA7

W34

no.CERC-96-3

c.3

\section{Iy Corps}

neers

Waterways Experiment

Station

\title{
Halloween Storm and Storm of 4-5 January 1992: Implications for the Occurrence of Similar Events
}

by Andrew W. Garcia

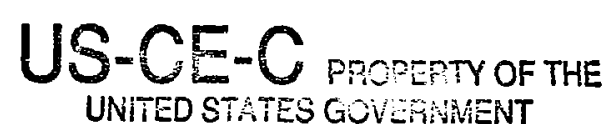

Approved For Public Release; Distribution is Unlimited

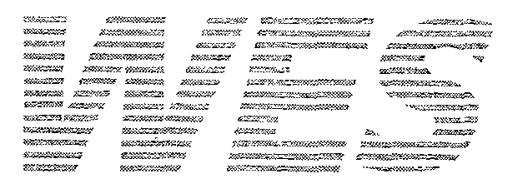

RESEARCH LIBRARY

US ARMY ENGINEER WATEPWAYS

EXPERIRENT STATION

VICKSBURG, MISSISSIPPI

Prepared for Headquarters, U.S. Army Corps of Engineers 
The contents of this report are not to be used for advertising, publication, or promotional purposes. Citation of trade names does not constitute an official endorsement or approval of the use of such commercial products. 
Halloween Storm and Storm of 4-5 January 1992: Implications for the Occurrence of Similar Events

by Andrew W. Garcia

U.S. Army Corps of Engineers

Watenways Experiment Station

3909 Halls Ferry Road

Vicksburg, MS 39180-6199

Final report

Approved for public release; distribution is unlimited 


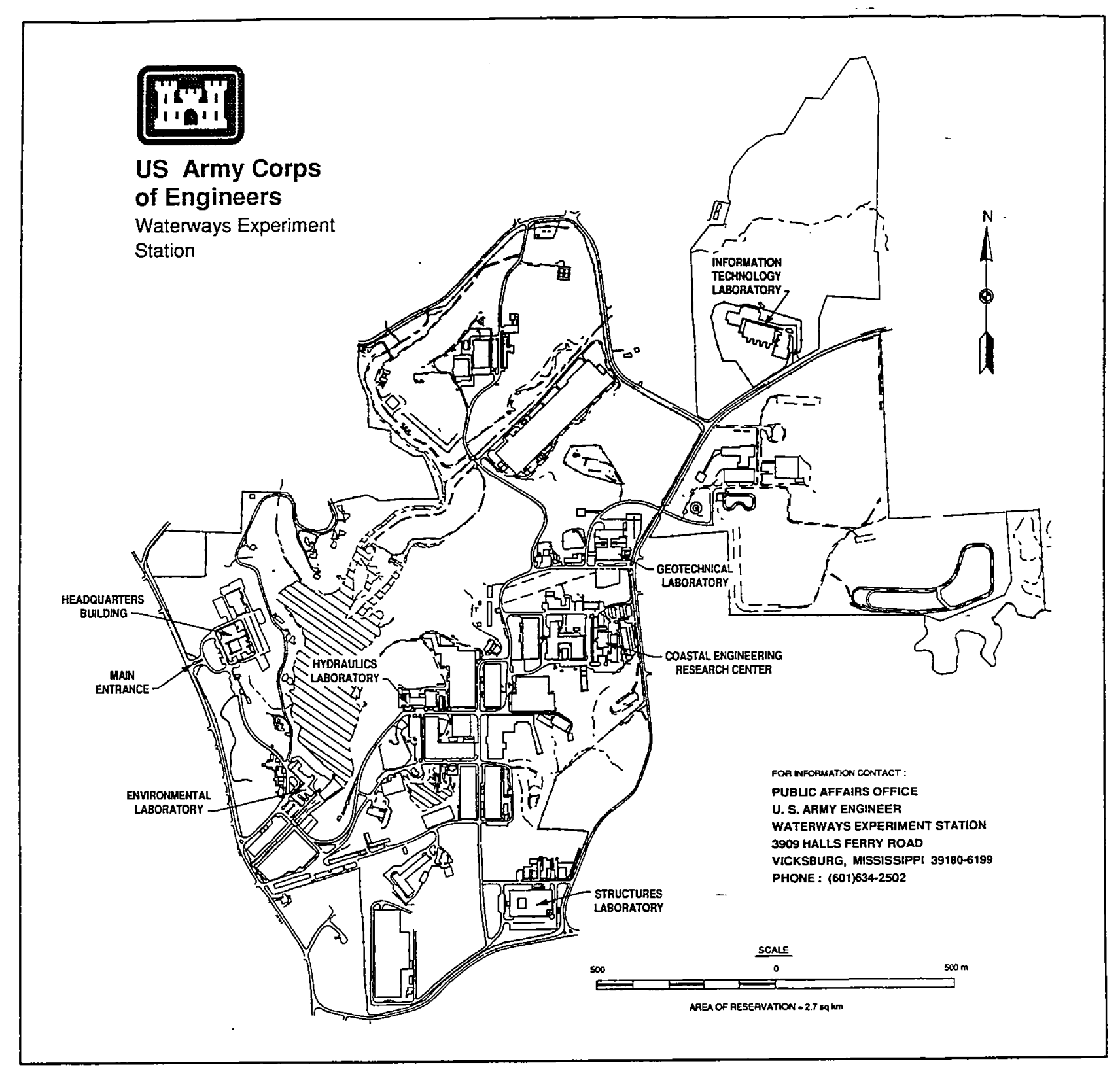

\section{Waterways Experiment Station Cataloging-in-Publication Data}

Garcia, Andrew W.

Halloween storm and storm of 4-5 January 1992 : implications for the occurrence of similar events / by Andrew W. Garcia ; prepared for U.S. Army Corps of Engineers.

55 p. : ill. ; $28 \mathrm{~cm}$. -- (Technical report ; CERC-96-3)

Includes bibliographic references.

1. Halloween Nor'easter, 1991. 2. Storms - Atlantic Coast (U.S.) I. United States. Army. Corps of Engineers. II. U.S. Army Engineer Waterways Experiment Station. III. Coastal Engineering Research Center (U.S. Army Engineer Waterways Experiment Station) IV. Title. V. Series: Technical report (U.S. Army Engineer Waterways Experiment Station); CERC-96-3.

TA7 W34 no.CERC-96-3 


\section{Contents}

Preface $\ldots \ldots \ldots \ldots \ldots \ldots \ldots \ldots \ldots \ldots \ldots \ldots \ldots \ldots \ldots \ldots, \mathbf{v i}$

1 -Introduction $\ldots \ldots \ldots \ldots \ldots \ldots \ldots \ldots \ldots \ldots \ldots \ldots \ldots \ldots \ldots$

2-Operational Analysis Depictions.$\ldots \ldots \ldots \ldots \ldots \ldots \ldots \ldots \ldots$

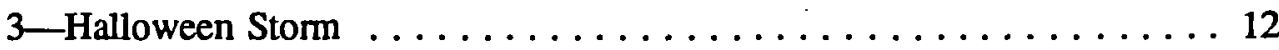

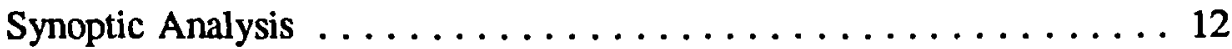

Vortex Interaction $\ldots \ldots \ldots \ldots \ldots \ldots \ldots \ldots \ldots \ldots \ldots \ldots \ldots \ldots$

Thermal Gradient Description . . . . . . . . . . . . . . 20

4 -Comparison of Halloween Storm with ERICA IOP-4 Event . . . . . 26

5 -Comparison of Halloween Stom with Blizzard of ' $78 \ldots \ldots \ldots 27$

6-Storm of 4-5 January 1992, Synoptic Analysis . . . . . . . . . 36

7-Westem Atlantic Retrograde Storms . . . . . . . . . . . 41

8 -Summary and Conclusions ................... 45

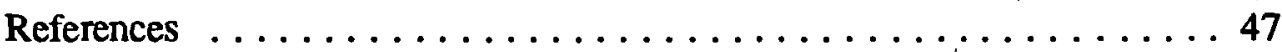

SF 298

\section{List of Figures}

Figure 1. Profiles of sea-level pressure at latitude $41^{\circ} \mathrm{N}$ latitude through the cyclone for the hemispheric, Sanders, and 00 -hr NGM analyses (from Pauley and Bramer (1992)) ......... 4

Figure 2. Central sea-level pressure for the cyclone as a function of reconstructed wave number retained as calculated from the Fourier amplitudes (from Pauley and Bramer (1992)) . . . . . . 5

Figure 3. Number of cyclogenesis events per $3 \times 10^{5} \mathrm{~km}^{2}$ during GALE, traveling cyclones only (from Neilsen and Dole (1992)) 
Figure 4. Number of cyclolysis events per $3 \times 10^{5} \mathrm{~km}^{2}$ during

GALE, traveling cyclones only (from Neilsen and Dole (1992)) . . . . . . . . . . . . . . . . 8

Figure 5. Distribution of maximum cyclones sizes during GALE (from Neilsen and Dole (1992)) . . . . . . . . . . . 9

Figure 6. Total period of time that cyclones could be tracked on weather charts as a function of the maximum radius attained by the cyclone (from Neilsen and Dole (1992)) . . . 10

Figure 7. Maximum 12-hr deepening (positive numbers indicate filling) distribution of traveling cyclones forming west of the Appalachians (continental cyclones) and east of the Appalachians (Atlantic cyclones) (from Neilsen and Dole (1992)) . . . . . . . . . . . . . . . . . . 11

Figure 8. 0000-hr UTC, 27 October 1991, surface analysis . . . . . . 13

Figure 9. 0000-hr UTC, 28 October 1991, surface analysis . . . . . . . 14

Figure 10. 0000-hr UTC, 29 October 1991, 500-mb height/temperature analysis ....................... 15

Figure 11. 0000-hr UTC, 29 October 1991, surface analysis . . . . . . 16

Figure 12. 1200-hr UTC, 29 October 1991, 850-mb height/temperature

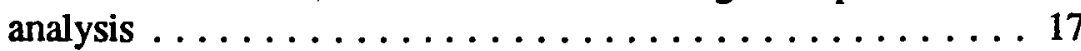

Figure 13. 0000-hr UTC, 30 October 1991, 500-mb height/temperature

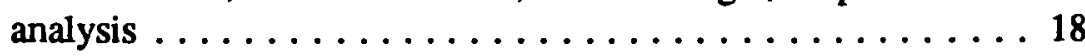

Figure 14. 1200-hr UTC, 30 October 1991, 500-mb height/temperature analysis ......................... 19

Figure 15. 1200-hr UTC, 30 October 1991, surface analysis . . . . . . 20

Figure 16. 1200-hr UTC, 31 October 1991, surface analysis . . . . . . . 21

Figure 17. 1200-hr UTC, 28 October 1991, 850-mb height/temperature

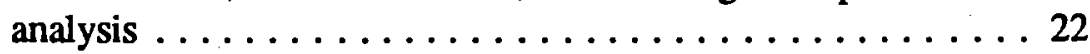

Figure 18. 0000-hr UTC, 29 October 1991, 850-mb height/temperature

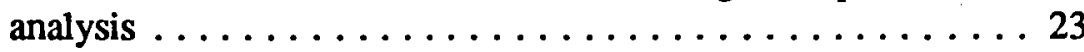

Figure 19. 1200-hr UTC, 29 October 1991, 850-mb height/temperature

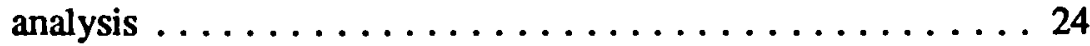

Figure 20. 0000-hr UTC, 30 October 1991, 850-mb height/temperature

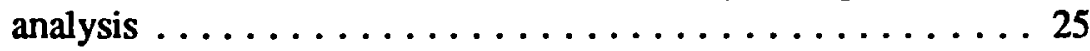

Figure 21. 1200-hr UTC, 5 February 1978, surface analysis . . . . . . 28

Figure 22. 1200-hr UTC, 5 February 1978, 500-mb height/temperature analysis . . . . . . . . . . . . . . . . . . . 29

Figure 23. 1800-hr UTC, 6 February 1978, surface analysis . . . . . . . 30 
Figure 24. 1200-hr UTC, 6 February 1978, 500-mb height/temperature

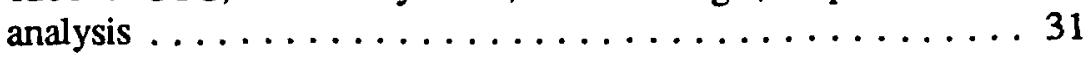

Figure 25. 1200-hr UTC, 7 February 1978, surface analysis . . . . . . 32

Figure 26. 1200-hr UTC, 7 February 1978, 500-mb height/temperature

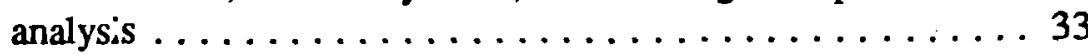

Figure 27. 1200-hr UTC, 8 February 1978, surface analysis . . . . . . 34

Figure 28. 1200-hr UTC, 8 Tebruary 1978, 500-mb height/temperature

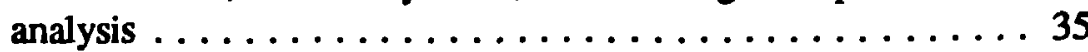

Figure 29. Wind and surface pressure data from National Park Service meteorological station on Assateague Island during 4-5 January 1992 storm . . . . . . . . . . . . . . . 37

Figure 30. Surface wind data at NDBC buoy 44009 during 4-5 January 1992 storm ....................... 38

Figure 31. Surface wind data at NDBC buoy 44012 during 4-5 January 1992 storm . . . . . . . . . . . . . . . . 39

Figure 32. 1220-hr UTC, 4 January 1992, surface pressure analysis . . . . 40

Figure 33. Average annual distribution of northwestern Atlantic storms with retrograde tracks, 1956-1991

\section{List of Tables}

Table 1. Mean Latitude and Longitude (degrees) and Mean Central Pressure (mb) for the F. Sanders (FS) Analyses . . . . . . . 3

Table 2. Comparison of Central-Pressure Values and Effective Resolution Needed to Reproduce the Central Pressure for Five Analyses $\ldots \ldots \ldots \ldots \ldots \ldots \ldots$

Table 3. Number of Northwestern Atlantic Storms, by Month, Having Retrograde Tracks in the 34-Year Period 1956-1991 . . . . . 42 


\section{Preface}

- The work described herein was authorized by Headquarters, U.S. Army Corps of Engineers (HQUSACE). The work was performed under the Episodic Events Work Unit 12112 of the Coastal Field Data Collection Program at the Coastal Engineering Research Center (CERC), U.S. Army Engineer Waterways Experiment Station (WES). Messrs. John H. Lockhart, Jr., Charles B. Chestnut, and Barry W. Holliday were HQUSACE Technical Monitors. Ms. Carolyn M. Holmes, CERC, was Program Manager of the Coastal Field Data Collection Program.

This study was performed by Dr. Andrew W. Garcia, Prototype Measurement and Analysis Branch (PMAB), Engineering Development Division (EDD), with assistance from Professor Carl W. Krietzberg, Drexel University, during the period March 1992 to December 1993. This report was prepared by Dr. Garcia. This study was performed under the administrative supervision of Dr. James R. Houston, Director, CERC; Mr. Charles C. Calhoun, Jr., Assistant Director, CERC; Mr. Thomas W. Richardson, Chief, EDD; and Mr. William L. Preslan, Chief, PMAB.

At the time of publication of this report, Director of WES was Dr. Robert W. Whalin. Commander was COL Bruce K. Howard, EN.

The contents of this report are not to be used for advertising. publication, or promotional purpases. Citation of trade names does not constitute an official endorsement or approval of the use of such commercial products. 


\section{Introduction}

During the winter of 1991-92, two intense storms, one large and of long duration, the other small and of short duration, caused extraordinary damage along the eastem seaboard of the United States. Specifically, the storms occurred on 29 October to 2 November 1991, and 4-5 January 1992. The most notable was that of 29 October to 2 November 1991, commonly referred to as the "Halloween Storm." In terms of its long duration and great extent of affected coastline, the Halloween Storm was indeed very unusual. Using historical water level data as a basis, at some locations it was the event of record (e.g., Nantucket, MA). At others it was calculated as relatively frequent, a 1-in-5 or 1-in-10 year event. Yet, there is general agreement in the geosciences community that storms such as the Halloween Storm occur less than once in 20 or perhaps 25 years. Clearly, as estimated from coastal water level elevations, the recurrence interval assigned to a storm depends upon the location of the measurement site in relation to the storm and therefore is not unique.

This report will explore factors other than coastal water levels which can be used to assign "frequency of occurrence" or "retum interval" to events such as the Halloween Storm. The approach used focuses on characteristics rather than effects of the event. These characteristics include the duration, intensity, size, area of origin, and track. In addition, meteorological records for approximately the past 30 years were examined for systems which exhibited track characteristics similar to those of the Halloween Storm. These systems were selected based upon genesis location within a specific geographic region and track characteristics similar to that of the Halloween Storm. Correlation of other characteristics will require further study and will be explained later. 


\section{Operational Analysis Depictions}

Evaluation of a particular storm event is typically based upon analysed weather charts. Since the predominant use of the charts is directed toward supporting forecast development, there is a strong constraint on the time available for chart preparation. The charts therefore are based upon meteorological data available at the time the charts are prepared, even though other relevant data may become available later. This process results in charts that may not incorporate all relevant data, which can lead to an incomplete or erroneous depiction of a particular event.

Several investigators (Davis and Emanuel 1988, Sanders 1990, Pauley and Bramer 1992) have noted that the National Meteorological Center's (NMC) limited-area fine mesh (LFM) and Nested Grid Model (NGM) tend to underforecast rapid maritime cyclogenesis (storm formation), while the LFM model at least is reasonably successful in forecasting rapid continental cyclogensis (Silberberg and Bosart 1982). This behavior suggests that some physical process is not being well treated by the model in oceanic situations, or poor quality data in the marine environment increase the difficulty of making accurate predictions. Studies by the aforementioned investigators indicate both effects may contribute to the forecast difficulties. While this report is not concemed with forecasting, the latter contributor (poor quality data) is relevant to the analyzed depiction of maritime storms.

The source of most analyzed weather data is the National Weather Service (NWS), and it is reasonable to assume that comparisons of storm events will be made based upon NWS analyses. In practice, however, it is quite common for oceanic storms, which cause damage or disruption to maritime shipping or coastal communities, to be analyzed in greater detail using reports and data not usually included in routine NWS analyses (e.g., Gyakum (1983). Events analyzed in this manner can differ in significant aspects from depictions of the same event prepared in a routine manner.

Sanders (1990) made a detailed comparison of what he termed research analyses versus both manual and automated NMC operational analyses. The comparison was based on 35 analyses of surface conditions during intensive observation periods (IOP) $1-5$ of the experiment on rapidly intensifying 
cyclones over the Atlantic (ERICA) (Hadlock and Krietzberg 1988). The comparisons were only in terms of the central positions and (minimum surface) pressures of lows occurring during ERICA. Thirty-three of the thirty-five analyses were at 6-hr intervals; the remaining two were at 3-hr intervals. The results of the comparison are summarized in Table 1. Note that all the operational analyses indicated a higher central pressure than Sanders' analyses. While this might be indicative of bias by Sanders toward deeper lows, a comparison of Sanders' analyses with research analyses independently prepared by G. Forbes showed only a +0.5-mb difference. Moreover, extreme cases of individual analyses showed differences of $20 \mathrm{mb}$ between the operational and Sanders analyses.

\begin{tabular}{|c|c|c|c|}
\hline Series & Bearing/distance & Pressure & $\mathbf{N}$ \\
\hline GF & $272 / 31(69)$ & $+0.5(2.5)$ & 35 \\
\hline $\mathrm{NH}$ & 066/11 (107) & $+0.6(4.0)$ & 29 \\
\hline NA & $063 / 08(131)$ & $+2.1(5.6)$ & 34 \\
\hline NGM & $152 / 34 .(181)$ & $+3.4(3.5)$ & 17 \\
\hline MRF & $217 / 45$ (179) & $+7.5(5.7)$ & 8 \\
\hline \multicolumn{4}{|c|}{$\begin{array}{l}\text { FS Analyses: } 37.6 \mathrm{~N}(4.7) 653.7 \mathrm{~W}(7.1) 987(20) \mathrm{N}=35 \\
1 \text { For the other analyses, mean geographic bearing (degrees) and distance (km) from this } \\
\text { position, and mean central-pressure deviation. Values in parentheses are RMS deviations } \\
\text { from the mean. From F. Sanders (1990). }\end{array}$} \\
\hline
\end{tabular}

As a more quantitative example of detailed versus operational analyses, a case study is used to examine the depiction of the minimum surface pressure, a commonly used measure of storm intensity. The minimum surface pressure is a useful example because at any given time, it is a unique scalar quantity, and therefore unambiguous. The study is of an extratropical cyclone, during IOP 4 of the ERICA (Hadlock and Krietzberg 1988) at $0000 \mathrm{hr}$ Universal Time Coordinate (UTC) 5 January 1989. Pauley and Bramer (1992) examine the effects of spatial resolution on depiction of the sea-level pressure profiles along a line of latitude (41 deg $\mathrm{N}$ ) passing through the storm. They used five analyses, but two were forecast analyses, therefore not relevant to the present discussion. Of the remaining three, one was based upon a detailed hand analysis of Prof. F. Sanders using all available ship, buoy, and reconnaissance aircraft data; the second was the NMC hemispheric analysis based upon operational weather charts; the third was the NGM forecast initialization analysis valid at $0000 \mathrm{hr}$ UTC, 5 January 1989. 
One objective of the comparison was to determine how well the different analyses depicted the accepted minimum central pressure $(936 \mathrm{mb})$ determined by Sanders. Figure 1 shows the latitudinal profiles of sea level pressure as determined using the different analyses. Some data interpolation and smoothing were performed on the hemispheric analysis in the vicinity of the cyclone center. Table 2 contains the values of the minimum sea level pressures derived from the different analyses. The 00 -hr NGM analysis, which most closely resembles a typical operational analysis, shows the minimum central pressure of the cyclone at that time to be $10 \mathrm{mb}$ higher $(946 \mathrm{mb})$, and the modified hemispheric analysis $4 \mathrm{mb}$ higher $(940 \mathrm{mb})$, than the Sanders analysis.

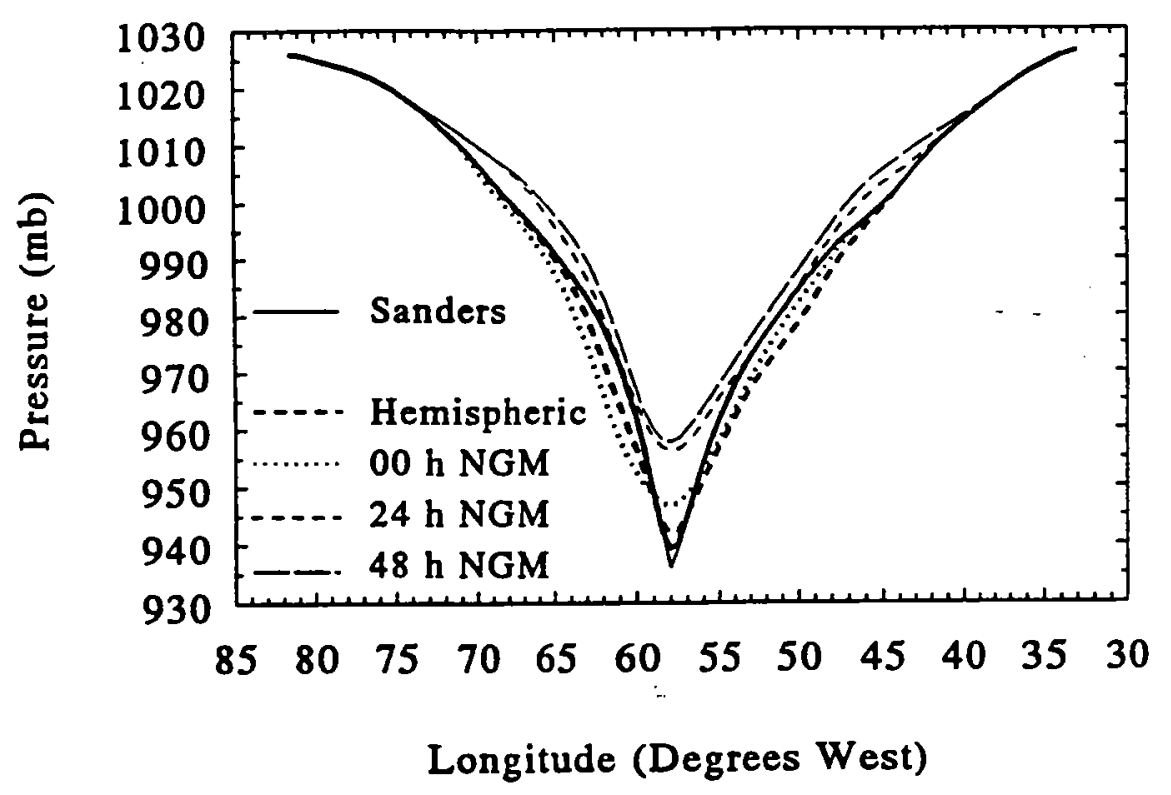

Figure 1. Profiles of sea-level pressure at $41^{\circ} \mathrm{N}$ latitude through the cyclone for the hemispheric, Sanders, and 00-hr NGM analyses (from Pauley and Bramer (1992))

A second objective of the Pauley and Bramer investigation was to estimate the effective spatial resolution of the analyses necessary to reproduce the minimum central pressure. This was done by Fourier decomposing the respective pressure profiles in wave number space, then recomposing the profiles with increasingly higher wave components until the original profiles were effectively reproduced. Figure 2 shows the sea-level pressure for each analysis as a function of maximum wave number retained. Note that up to about wave number 30 (equivalent wavelength of $1,333 \mathrm{~km}$ ), all three analyses show equally increasing resolution. The equivalent wavelength here is the circumference of the 41-deg latitude circle divided by the wave number. Table 2 shows the minimum wave numbers and effective wavelength of each analysis 


\begin{tabular}{|c|c|c|c|}
\hline \multicolumn{4}{|c|}{$\begin{array}{l}\text { Table } 2 \\
\text { Comparison of Central-Pressure Values and Effectlve Resolu- } \\
\text { tion Needed to Reproduce the Central Pressure for Five } \\
\text { Analyses }\end{array}$} \\
\hline Analysis & Central pressure (mb) & Wave number & Wavelength $(\mathrm{km})$ \\
\hline Hemispheric & 940 & 96 & 315 \\
\hline Sanders & 936 & 148 & 204 \\
\hline 00-h NGM & 946 & 38 & 795 \\
\hline 24-h NGM & 956 & 46 & 657 \\
\hline 48-h NGM & 957 & 51 & 592 \\
\hline \multicolumn{4}{|c|}{$\begin{array}{l}1 \text { Effective resolution is defined as the minimum number of wave numbers, or equivalent } \\
\text { wavelength, at latitude } 41^{\circ} \mathrm{N} \text {. The } 24-\mathrm{hr} \text { and } 48 \text {-hr NGM analyses are forecasts, therefore not } \\
\text { relevant to the data depiction issue (from Pauley and Bramer (1992)). }\end{array}$} \\
\hline
\end{tabular}

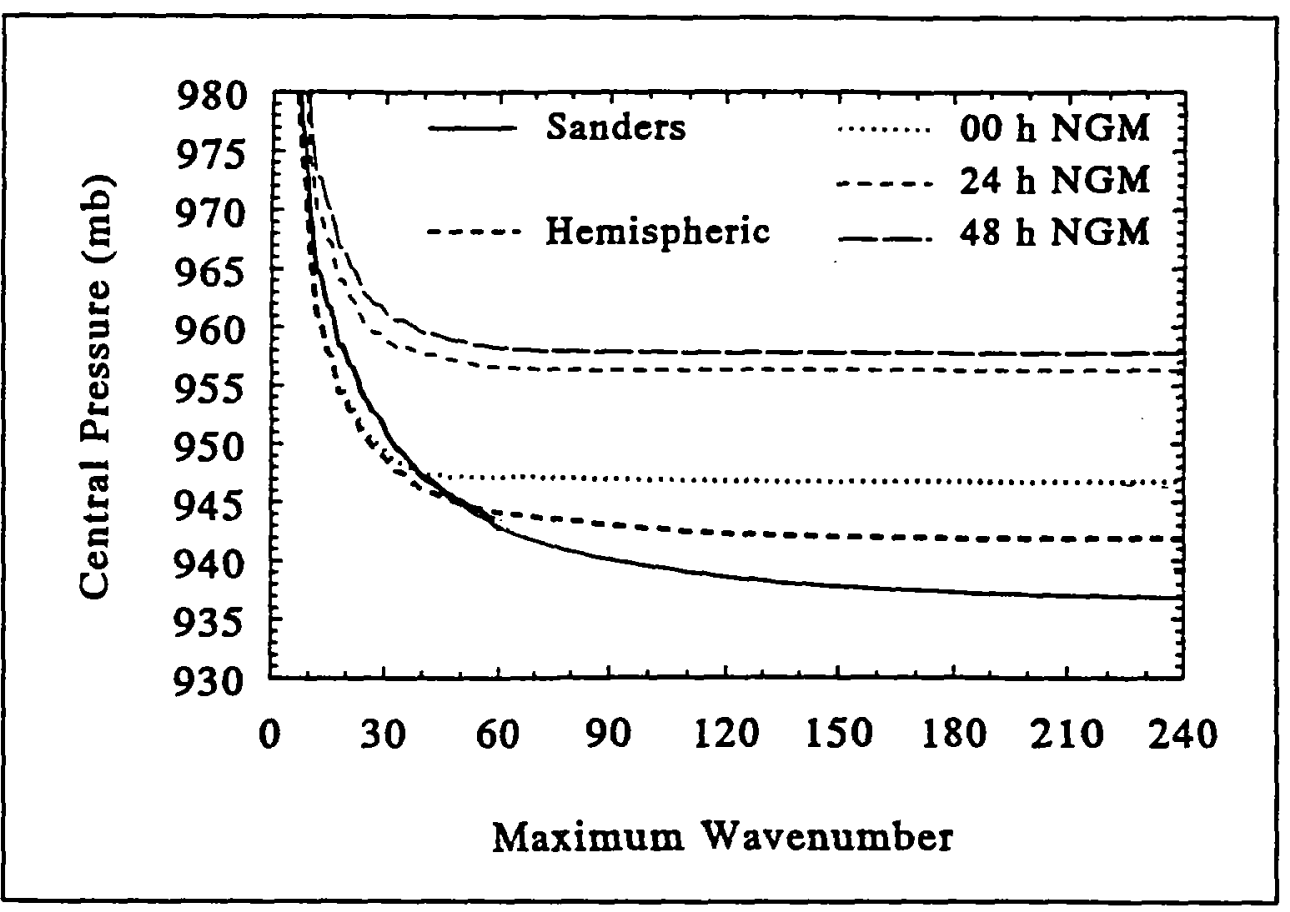

Figure 2. Central sea-level pressure for the cyclone as a function of reconstructed wave number retained as calculated from the Fourier amplitudes (from Pauley and Bramer (1992))

necessary to reproduce the minimum surface pressure. At wave number 148 , the recomposed profile reproduces that of Sanders within $0.8 \mathrm{mb}$. Note that the equivalent wavelengths of the hemispheric and $00-\mathrm{hr}$ NGM are $315 \mathrm{~km}$ and 00-hr NGM $795 \mathrm{~km}$, respectively, whereas that of Sanders' analysis is $204 \mathrm{~km}$. 
These studies imply that the resolution of standard operational surface analyses in the oceanic environment for these types of events is somewhere between $2 / 3$ and $1 / 4$ that of the best available practice. The object here is not to denigrate the operational analyses, which typically do not have the benefit of the ship reports and buoy data incorporated in the research analyses.

Rather, it is to emphasize and substantiate the fact that the selection of events based upon characteristic parameters can be biased by the analysis procedures used to depict the event. Although this discussion has been primarily confined to the single parameter of sea-level pressure, the pressure (and the pressure tendency) parameter is significant in that it is highly correlated with the geotrophic windspeed (and the geotrophic windspeed tendency) (Weinstein and Sanders 1989). Indeed, Weinstein and Sanders (1989) acknowledge that winds are of more interest to the maritime community than pressure. The question then arises, why not use wind data directly to aid in classification of events? The answer, unfortunately, is that surface wind data in these events are scarce, typically forcing wind estimates to be inferred from the pressure field.

In addition to the minimum sea level pressure, size is another physical measure of a storm event. Size is more difficult to quantify objectively than minimum pressure because the definition of size is, to some extent, arbitrary. Nielsen and Dole (1992) consider several different measures of size. These include (a) distance from the cyclone center to the nearest high pressure center, (b) distance from the cyclone center to the nearest adjacent cyclone center, (c) distance from the cyclone center to the nearest col (saddle point) of sea level pressure, or (d) the horizontal area encompassed by the largest closed isobar about the cyclone. Definitions (a), (b), and (d) are rejected because of difficulties caused by ambiguities when applied to some scenarios. Definition (c) was adopted and termed the RADIUS because it is effectively the distance from the system center to the outermost closed isobar.

Nielsen and Dole (1992) applied this size criterion to virtually all cyclones that formed during and within the boundaries of the Genesis of Atlantic Lows Experiment (GALE; 13 January - 16 March 1986). Any analyzed low that appeared on two consecutive charts $(3 \mathrm{hr}$ or $6 \mathrm{hr}$ depending upon geographic area) was included in the study. For climatological documentation purposes, all cyclones were classed as stationary if their terminal (lysis) position was within $400 \mathrm{~km}$ of their genesis position; all others were classed as travelling cyclones. Because the stationary cyclones tended to form and die over the eastem continental United States, they are not relevant to the present study and will not be discussed further.

Recognizing the depiction problem caused by oceanic data scarcity pointed out by Pauley and Bramer (1992), and others, Nielsen and Dole subjectively re-analyzed the operational charts and included additional available data. They found that the operational analyses often did not identify a developing surface low until it was 2 or $3 \mathrm{mb}$ below the surrounding field. This tendency caused the operational analyses possibly to miss small systems in early stages of development. The effect of these omissions, however, tended to be limited to small, short-lived cyclones and did not significantly affect the results 
pertaining to the larger, deeper systems. Figure 3 shows the cyclogenesis and Figure 4 shows the cyclolysis density of travelling cyclones during GALE. Note the maximum in the vicinity of the Chesapeake Bay area with a secondary maximum in the westem Atlantic. Figure 5 shows the distribution of maximum cyclone sized during GALE.

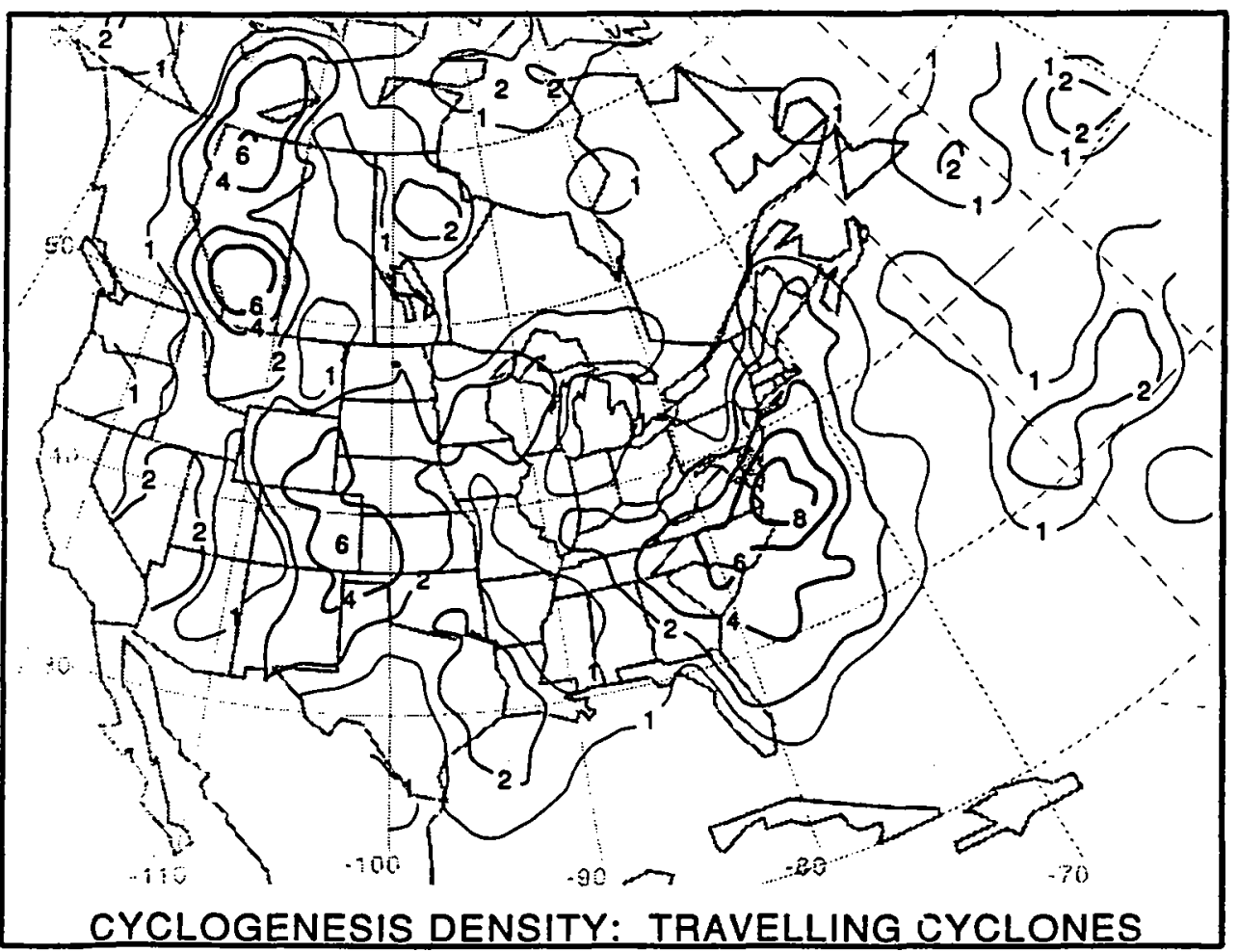

Figure 3. Number of cyclogenesis events per $3 \times 10^{5} \mathrm{~km}^{2}$ during GALE, traveling cyclones only (from Neilsen and Dole (1992))

A 12-mb pressure deficit (relative to the nearest adjacent col) was arbitrarily selected as representing prominent cyclones; at a 4-mb contour interval this deficit would be depicted by three closed isobars. The average radius of systems attaining a 12-mb deficit was approximately $1,500 \mathrm{~km}$. During the GALE, only about 20 percent of all the systems that formed attained the characteristics of prominent cyclones. Separating all formed cyclones into prominent and non-prominent classes showed that the small-scale, non-prominent cyclones had a mean duration of $18 \mathrm{hr}$, the prominent cyclones had a mean duration of $83 \mathrm{hr}$. Figure 6 shows the relationship between the maximum radius attained and the cyclone duration (length of time the system appeared on weather charts). Note that there are a comparatively greater number of long-lived small cyclones than there are short-lived large cyclones.

Cyclone intensification is commonly estimated by the temporal change in central pressure (deepening). This measure of intensification is reliable when the far-field pressure remains constant; then the deepening will equal the spatial pressure deficit. However, when more than one system is in the 


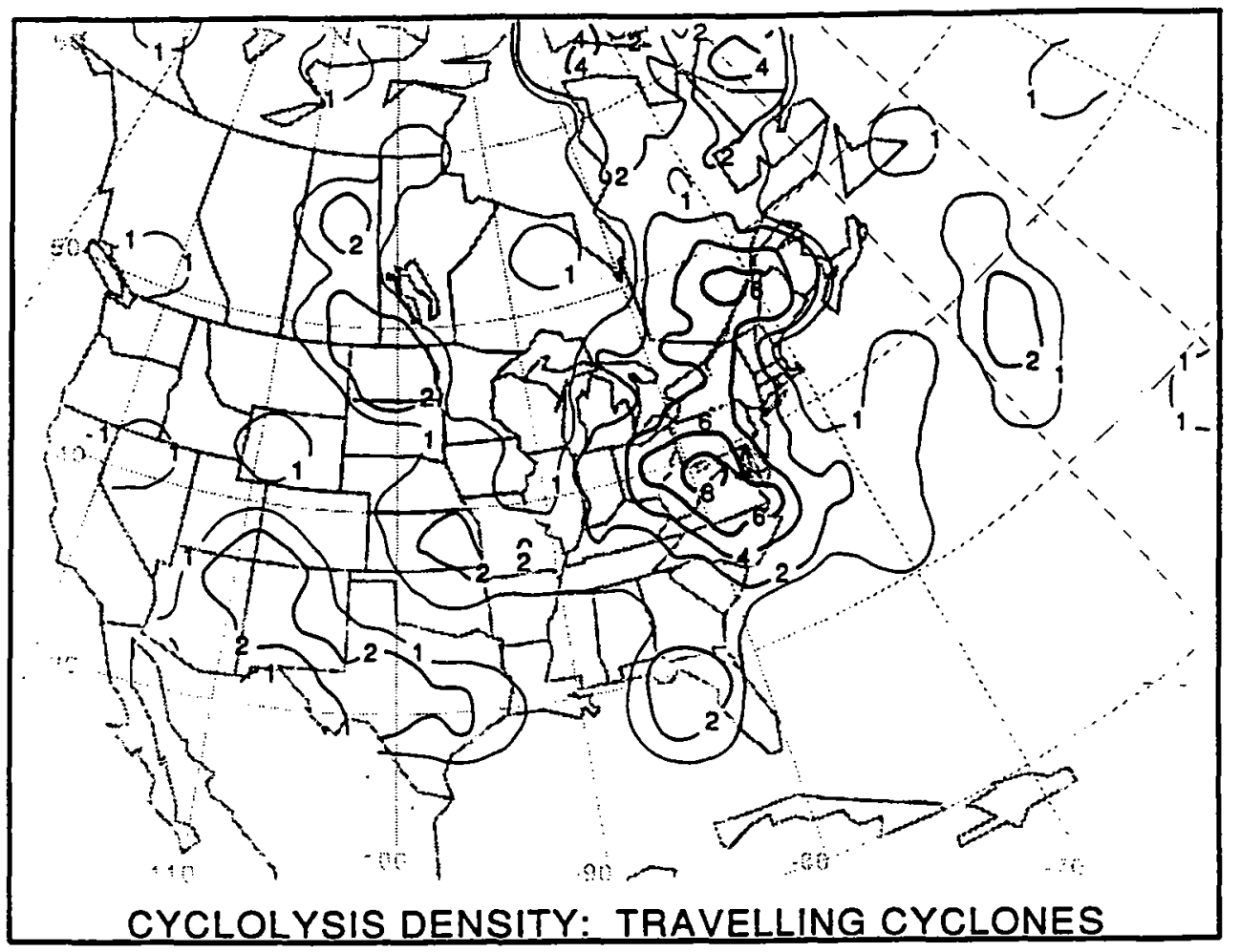

Figure 4. Number of cyclolysis events per $3 \times 10^{5} \mathrm{~km}^{2}$ during GALE, traveling cyclones only (from Neilsen and Dole (1992))

vicinity, the system will tend to interact and coalesce, following the geopotential height falls. In this case, the pressure deficit will be less than the deepening because the far-field pressure will tend to fall as well. Nielsen and Dole concluded that “....while strong deepening does not necessarily imply a large pressure deficit, a large pressure deficit is a good indicator of rapid prior deepening." This statement implies that when a large pressure deficit appears on a chart but does not appear on earlier charts, it is likely that a system was forming but went undepicted on the earlier charts. Figure 7 shows the maximum 12-hr deepening of traveling cyclones by continental and Atlantic classes. Note that Atlantic cyclones tend to exhibit much greater deepening than do continental cyclones. That the rapid deepening cyclones are almost exclusive to an oceanic regime is consistent with the findings of Sanders and Gyakum (1980).

The preceding section of this chapter discusses issues that concern the identification and selection of significant extratropical cyclone events based upon available meteorological information. The magnitudes of the factors that are considered in the selection such as size, intensity, duration, and position are shown to depend upon the analyzed depiction of the event. Events that cause substantial coastal damage or have significant effects on maritime shipping are likely to be analyzed in greater detail, resulting in more accurate 


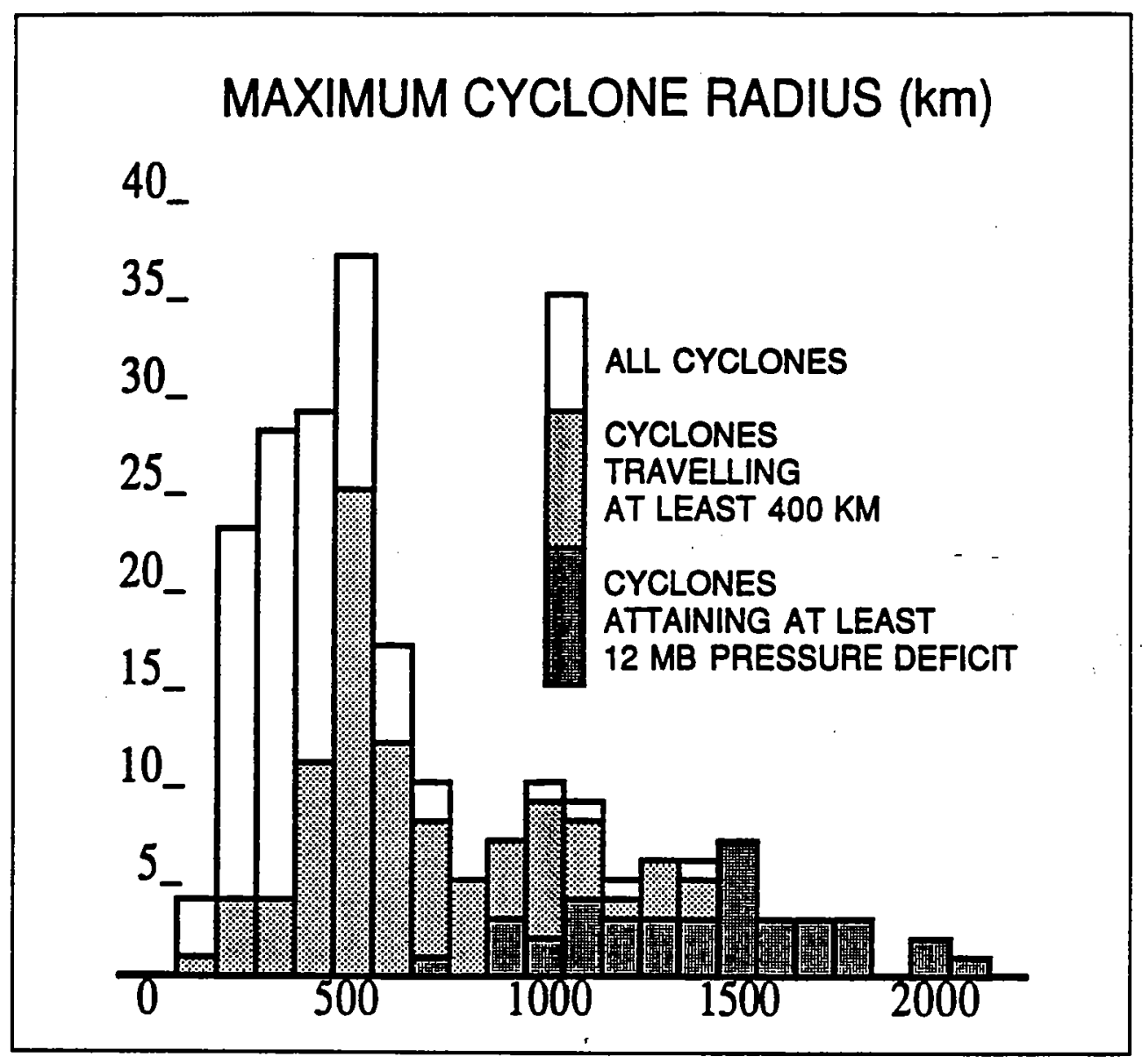

Figure 5. Distribution of maximum cyclone sizes during GALE (from Neilsen and Dole (1992))

depicitions than large or severe events analyzed in a routine manner. Based upon pressure and wind data, the detailed analyses tend to show events as more intense (at least over some fraction of the area involved) and of greater duration. A procedure should be developed to minimize the bias toward higher minimum pressures, shorter durations, and perhaps smaller size that can result from unedited use of the operational analyses. The procedure should consider the results of the studies summarized in this report section. 


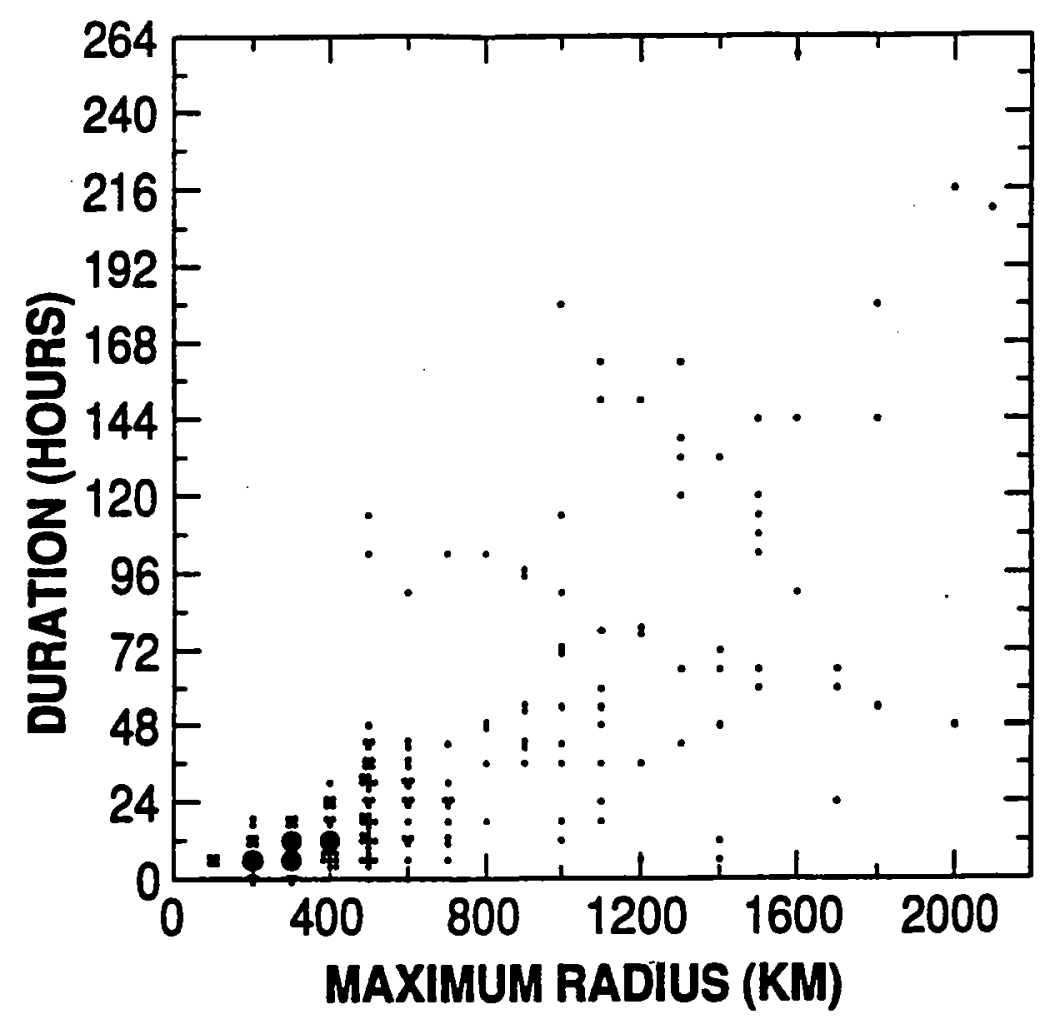

Figure 6. Total period of time that cyclones could be tracked on weather charts as a function of the maximum radius attained by the cyclone (from Neilsen and Dole (1992)) 


\section{Maximum 12-Hour Deepening (mb) Travelling Cyclones only}
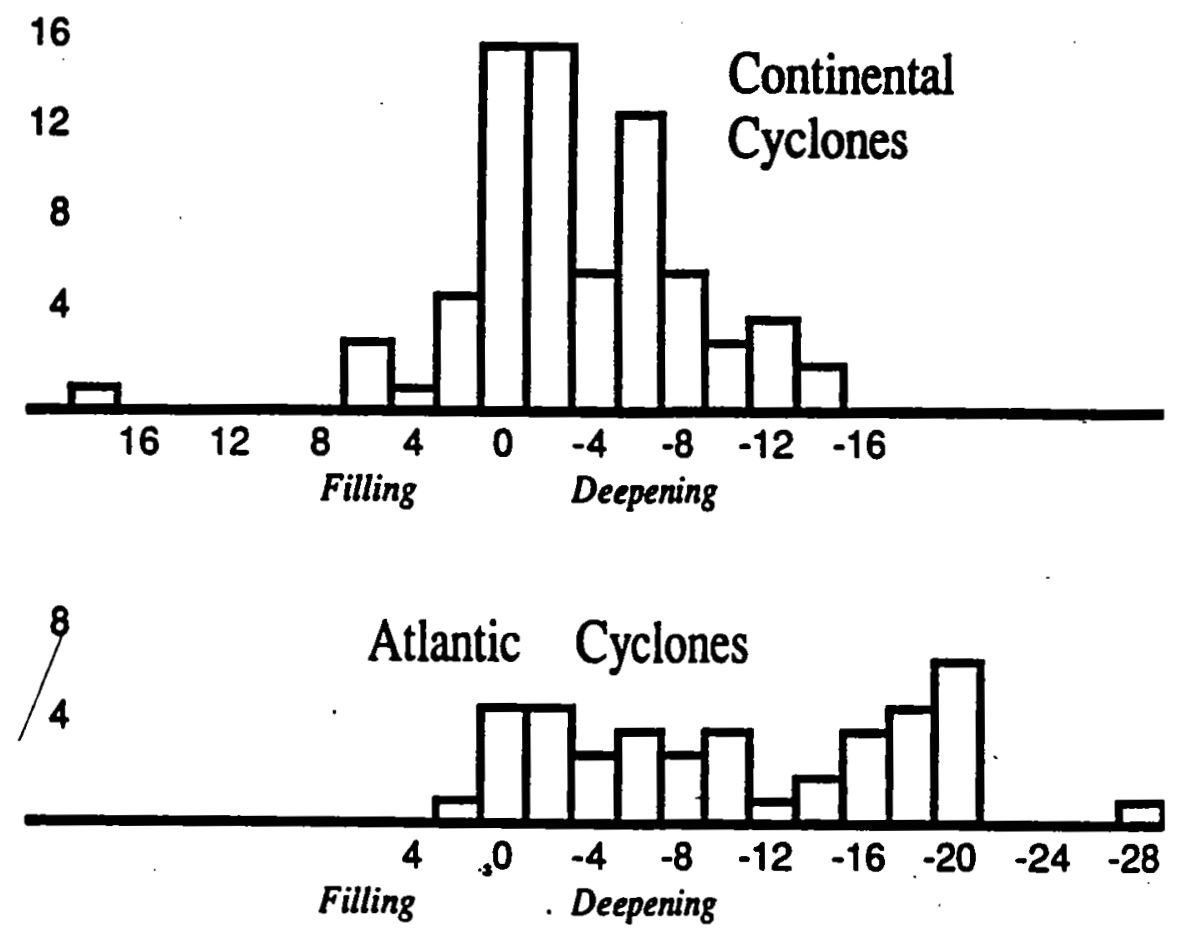

Figure 7. Maximum 12-hr deepening (positive numbers indicate filling) distribution of traveling cyclones forming west of the Appalachians (continental cyclones) and east of the Appalachians (Atlantic cyclones) (from Neilsen and Dole (1992)) 


\section{Halloween Storm}

\section{Synoptic Analysis}

The genesis of the storm of 28 October to 2 November 1991 (the "Halloween Storm") involved three significant meteorological features: (a) the subtropical low that evolved into Hurricane Grace; (b) a near-record high-pressure (1046-mb) anticyclone that developed in the vicinity of the Hudson Bay region of Canada, and (c) a low-pressure region that formed over the Great Lakes along the front accompanying the strong anticyclone to the north. Figure 8 (National Oceanic and Atmospheric Administration 1992) shows the surface analysis at $0000 \mathrm{hr}$ UTC, 27 October 1993. One day later, at $0000 \mathrm{hr}$ UTC, 28 October (Figure 9), the sub-tropical low had intensified to hurricane status and been named Grace, the low-pressure region had moved northeastward to the Canadian Maritimes, and the anticyclone had moved to the southeast, thereby increasing the pressure differential along the northeasterm North America coastline. During the next $24 \mathrm{hr}$ (to $0000 \mathrm{hr}$ UTC, 29 October), interaction of the surface low with an upper level trough located to the west of the low (see Figures 10 and 11) promoted rapid development of the surface low. Indeed, during the 12-hr period from $1200 \mathrm{hr}$ UTC, 28 October to $0000 \mathrm{hr}, 29$ October, the minimum surface pressure dropped $14 \mathrm{mb}$ from $1,012 \mathrm{mb}$ to $998 \mathrm{mb}$, a rate of decrease approximating that of a rapidly intensifying hurricane.

As the surface low intensified and moved off the coast, it began to entrain warm, moist air from the outer regions of Grace. The warm moist air from Grace, coupled with the cold, dry air flowing in from the strong anticyclone to the northwest markedly increased the baroclinic contrast (Figure 12). By $0000 \mathrm{hr}$ UTC, 30 October, the minimum surface pressure had decreased to $983 \mathrm{mb}$, a 15-mb drop during the previous $24 \mathrm{hr}$. Meanwhile, the upper level trough had deepened to a closed low and was positioned near longitude $65^{\circ} \mathrm{W}$, still to the west of the surface low (Figure 13). During the next $12 \mathrm{hr}$ the surface low continued to intensify and by $1200 \mathrm{hr}$ UTC, 30 October had reached its lowest central pressure of $972 \mathrm{mb}$. At this time the 500-mb level low was located just slightly west of the surface low (Figures 14 and 15).

By $0000 \mathrm{hr}$ UTC, 31 October 1991, the system had begun to fill, with the minimum central pressure rising to $982 \mathrm{mb}$, but moving to the west, which 


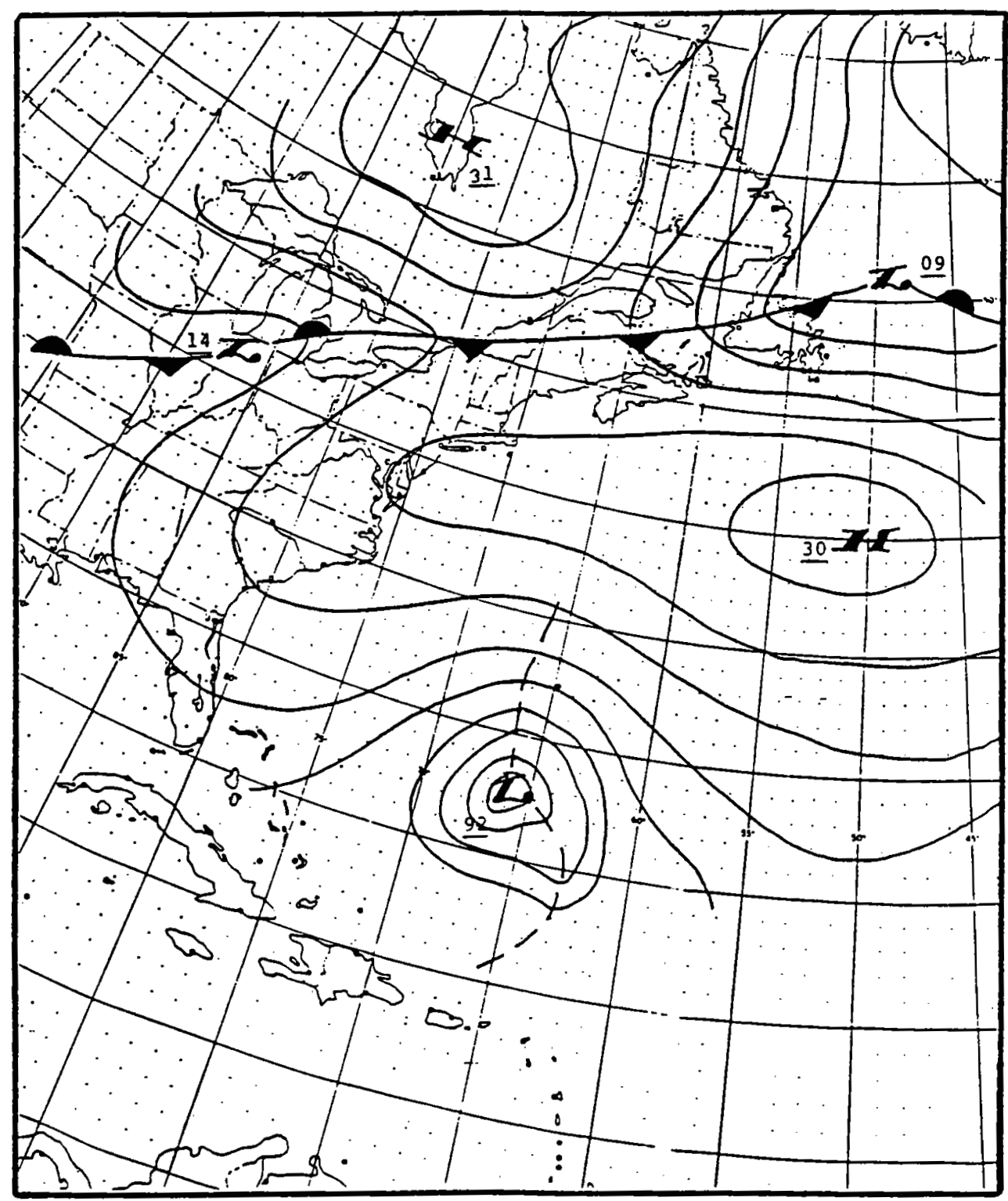

Figure 8. 0000-hr UTC, 27 October 1991, surface analysis

brought it closer to the United States east coast. The system continued to fill and move westward during the next $12 \mathrm{hr}$, by $1200 \mathrm{hr}$ UTC 31 October, the minimum central pressure had risen to $992 \mathrm{mb}$ (Figure 16). The upper level and surface lows were now co-located, and the system was beginning to weaken with the minimum central pressure rising to $998 \mathrm{mb}$. Although wave conditions were beginning to moderate, the storm was still generating strong northeast winds along the affected U.S. coastline. As the system drifted westward, it moved over warm Gulf Stream waters and began to re-intensify with the minimum central pressure dropping to $994 \mathrm{mb}$. By 2 November the storm had moved northward toward Nova Scotia, leaving the influence of the Gulf Stream, and begun to dissipate. 


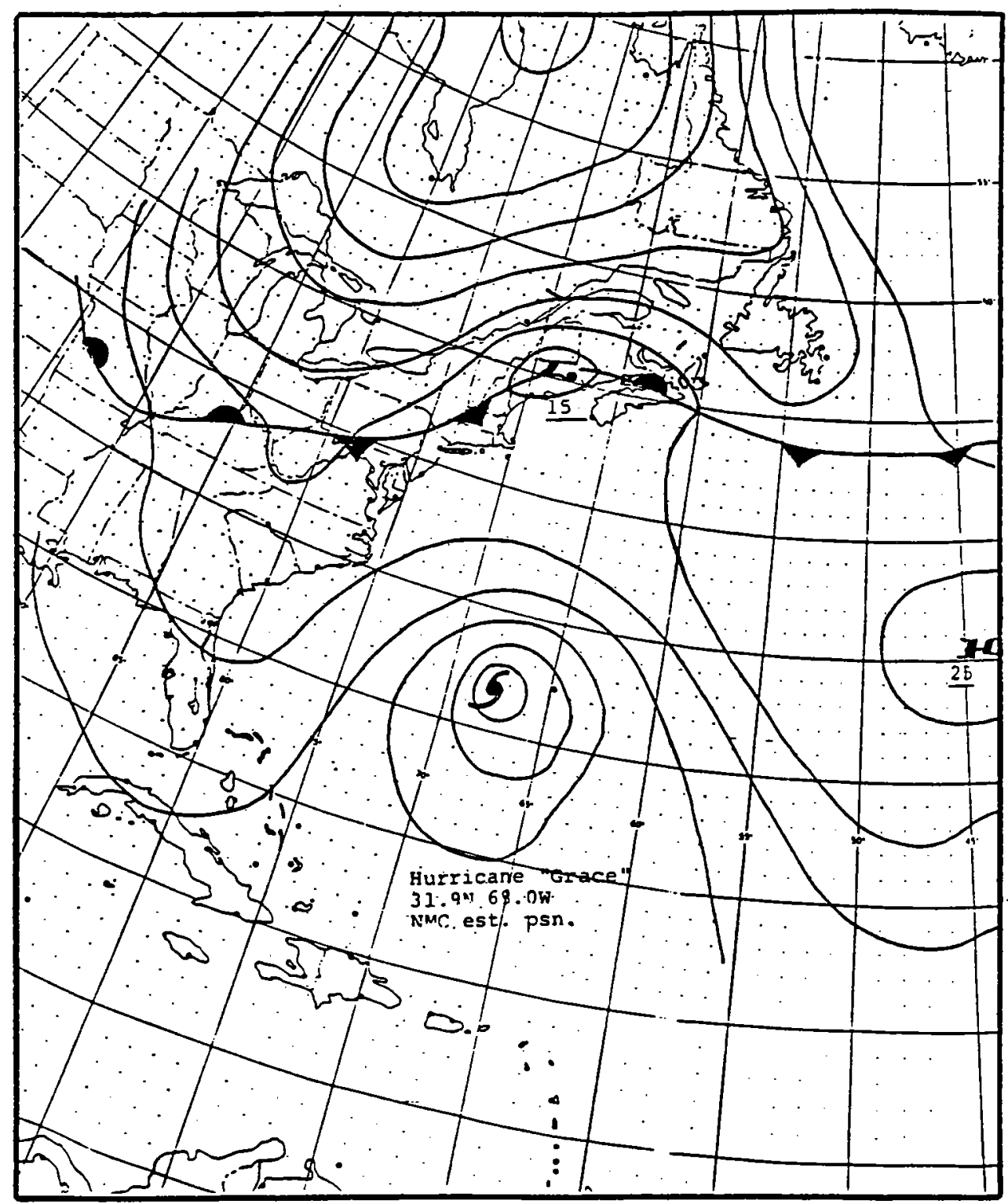

Figure 9. 0000-hr UTC, 28 October 1991, surface analysis

\section{Vortex Interaction}

In terms of intensification and movement, the early genesis stages of the Halloween storm followed the classical description of extratropical cyclone formation (e.g., Palmen and Newton (1969)), but also exhibited characteristics consistent with results of recent studies which indicate both upper-level forcing and lower-level moisture can be important contributors to cyclogenesis (Krietzberg 1991). The interaction of a surface low with an upper-level trough located to the west which results in rapid intensification has been elegantly 


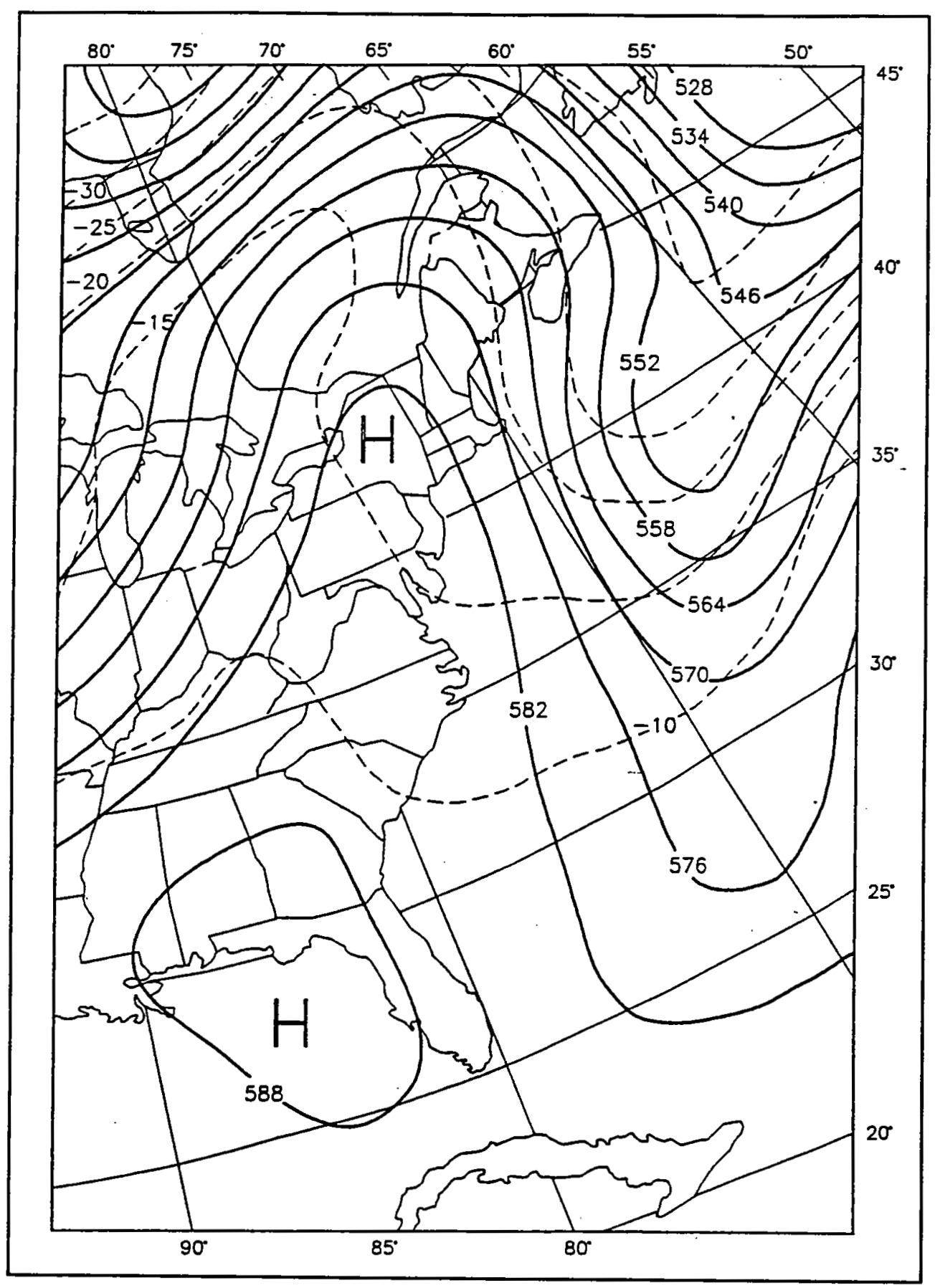

Figure 10. 0000-hr UTC, 29 October 1991, 500-mb heighttemperature analysis

treated by Bleck (1990). The basis of Bleck's treatment stems from a hypothesis advanced by Hoskins, McIntyre, and Robertson (1985), and involves the mutual amplification of quasi-geostrophic positive vorticity perturbations $(P V s)$ in the presence of baroclinic instability. Determination of the value of $P V$ over a specified volume is given by 


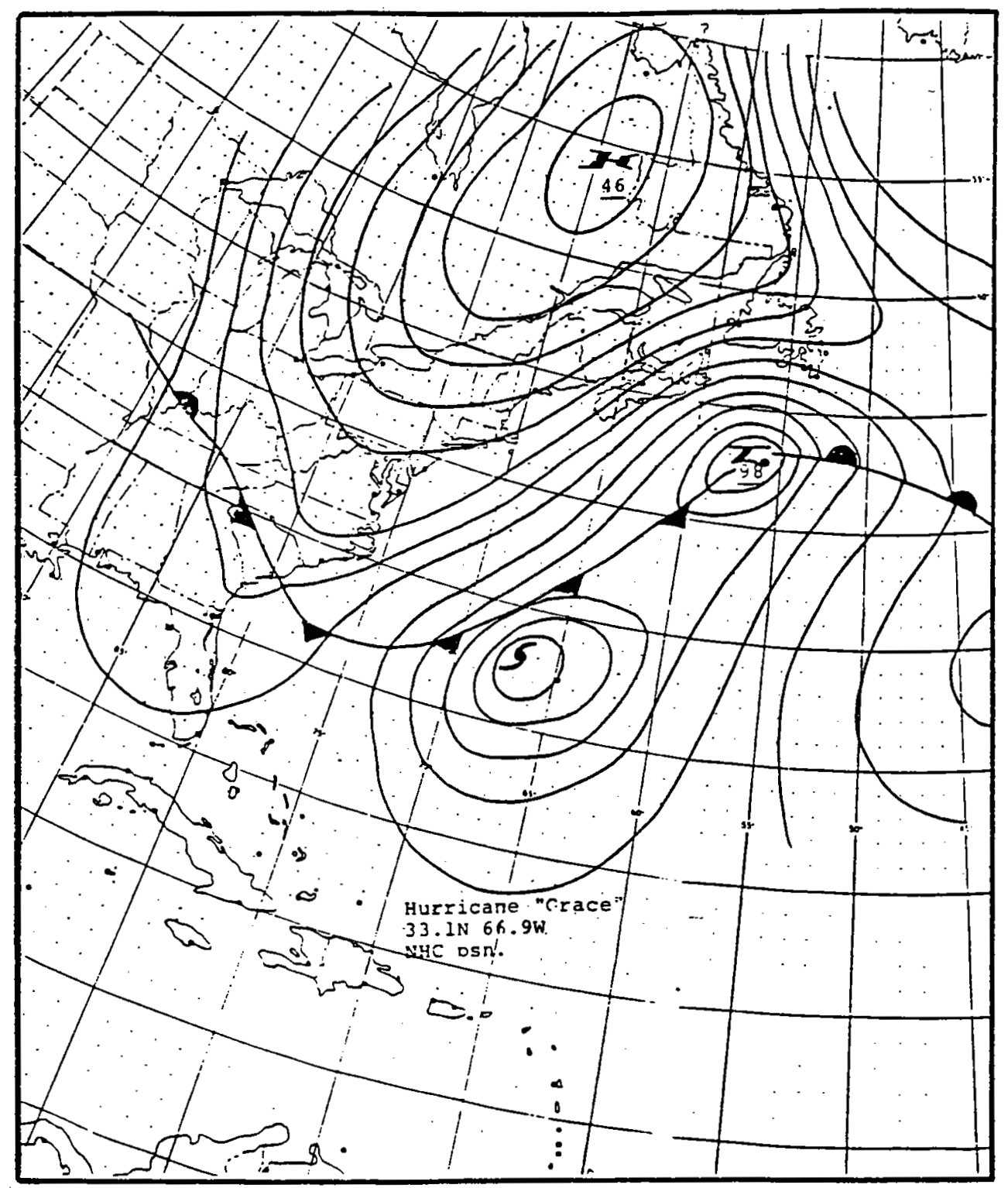

Figure 11. 0000-hr UTC, 29 October 1991, surface analysis

$$
P V=\int_{p_{l}}^{p_{b}} \frac{\zeta_{\theta}+f}{-\partial p / \partial \theta} d x d y d p
$$

where $\theta$ is the potential temperature, $\zeta_{\theta}$ is the relative vorticity in isentropic coordinates, and $f$ is the Coriolis parameter. The problem with application of this expression is that the $d p$ term in the integrand causes the expression to go to infinity at the surface (essentially division by zero). By assuming that $\theta$ is monotonic in $p$, then 


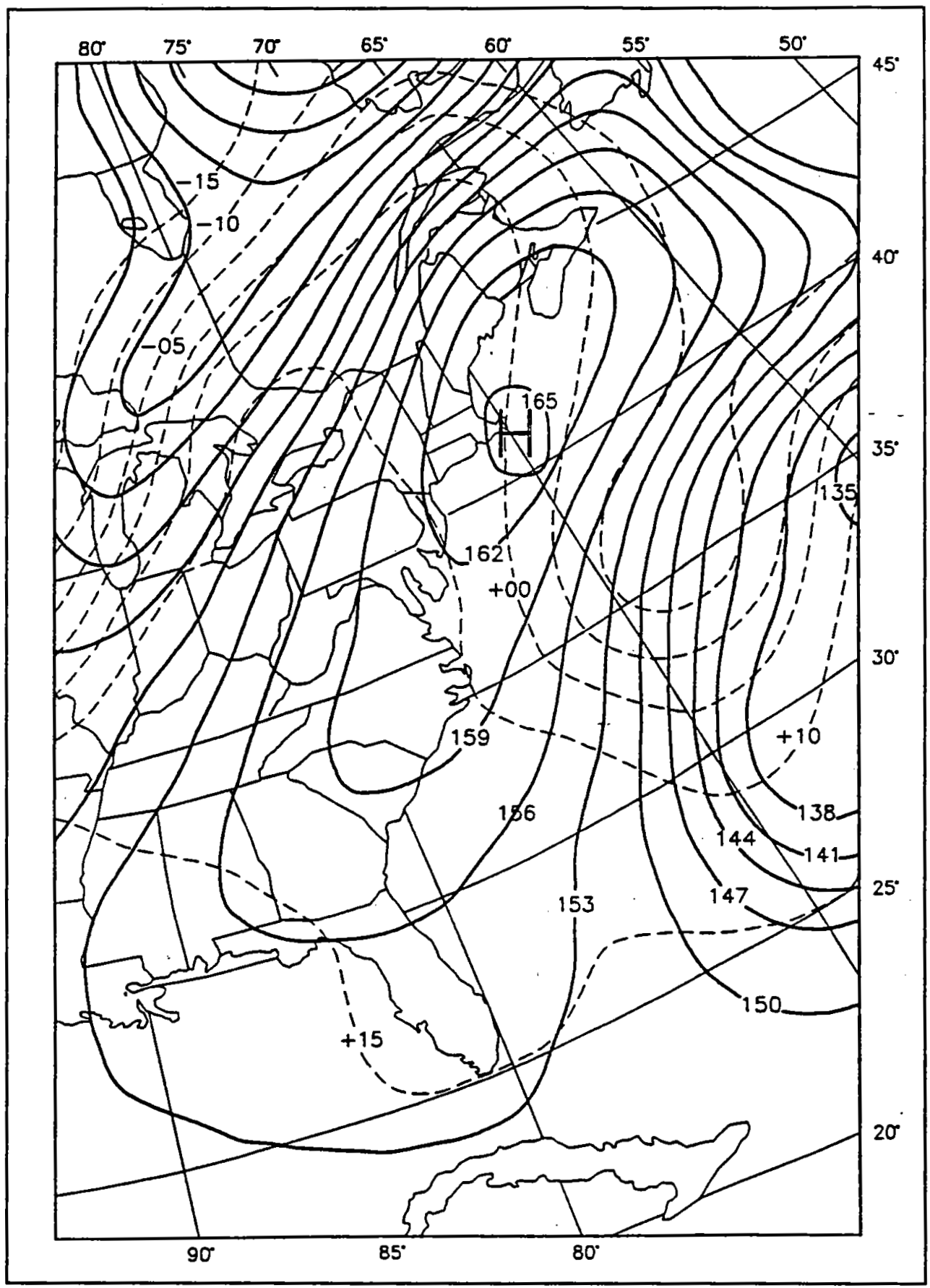

Figure 12. 1200-hr UTC, 29 October 1991, 850-mb height/temperature analysis

$$
d \theta=\left(\frac{\partial p}{\partial \theta}\right)^{-1} d p
$$

Substituting (2) into (1) transforms the integral into 


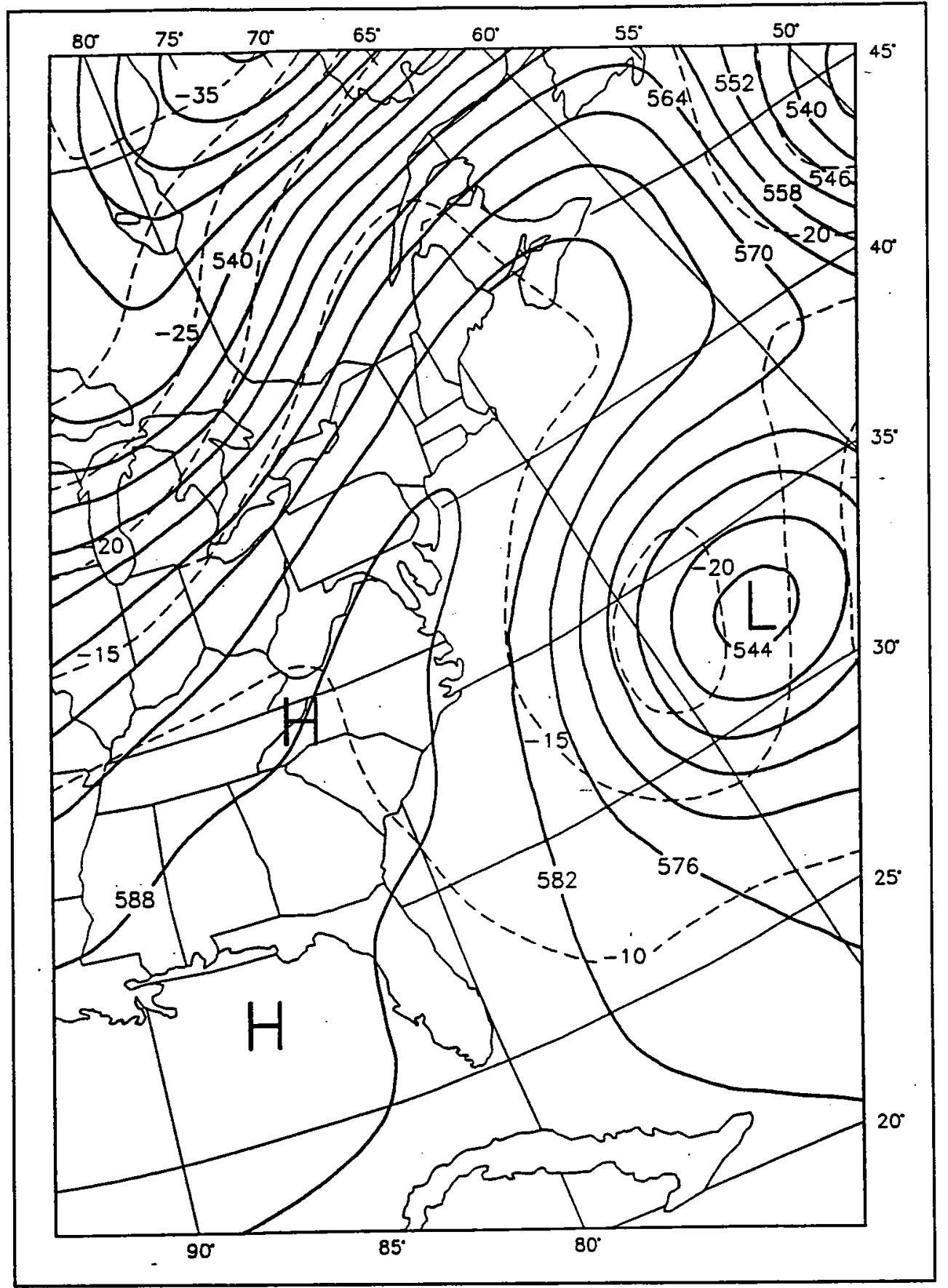

Figure 13. 0000-hr UTC, 30 October 1991, 500-mb heighttemperature analysis

$$
P V=\int_{\theta b}^{\theta t}\left(\zeta_{\theta}+f\right) d x d y d \theta
$$

which is well-conditioned and can be numerically integrated. 


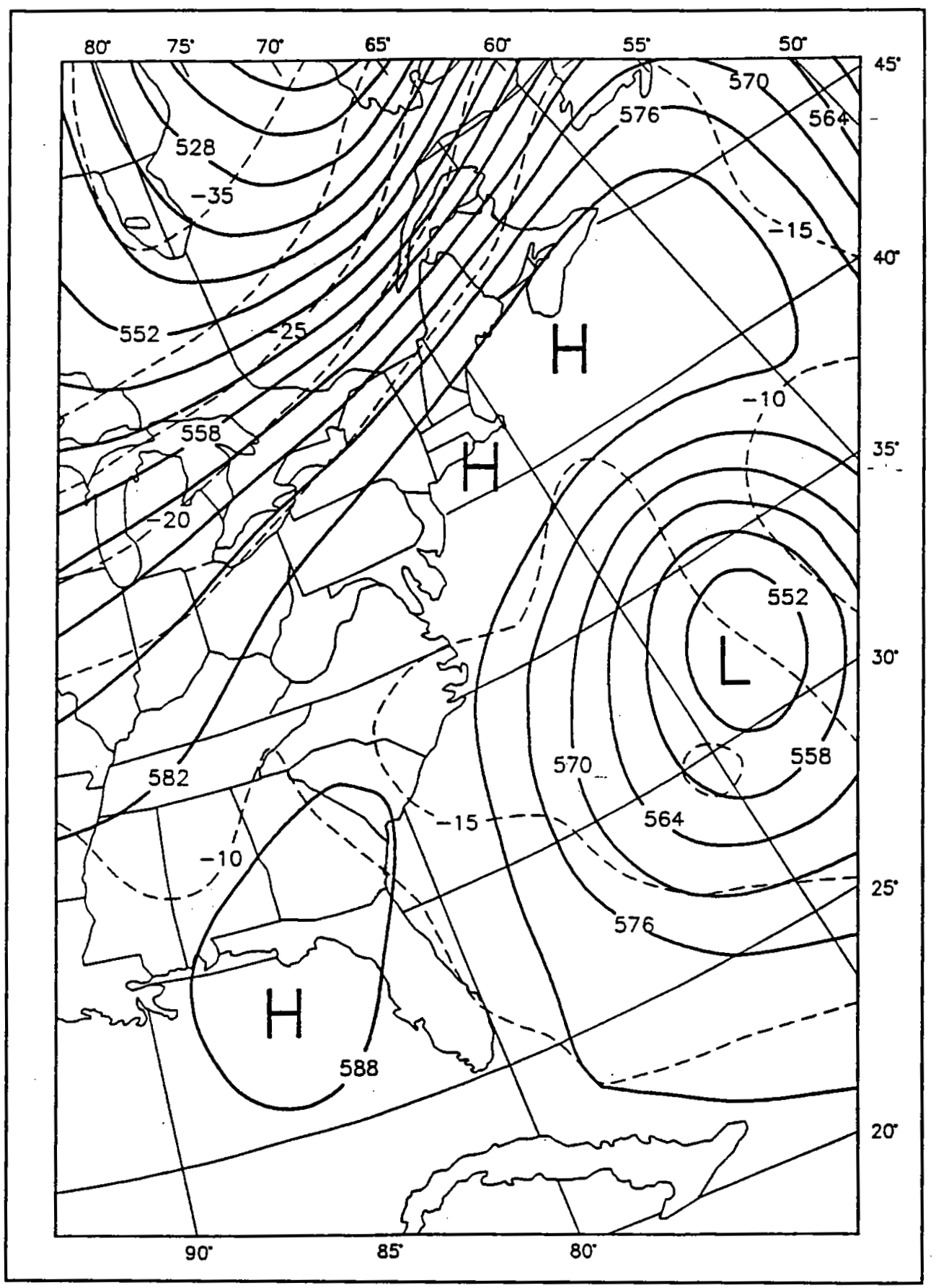

Figure 14. 1200-hr UTC, 30 October 1991, 500-mb height/temperature analysis

Application of (3) to the Halloween Storm to demonstrate the interaction of the upper-level and surface lows as a significant contributor to the storm formation is left for a later report.

The upper-level low is significant not only to the genesis of the Halloween Storm but also to the motion. In the absence of significant synoptic steering 


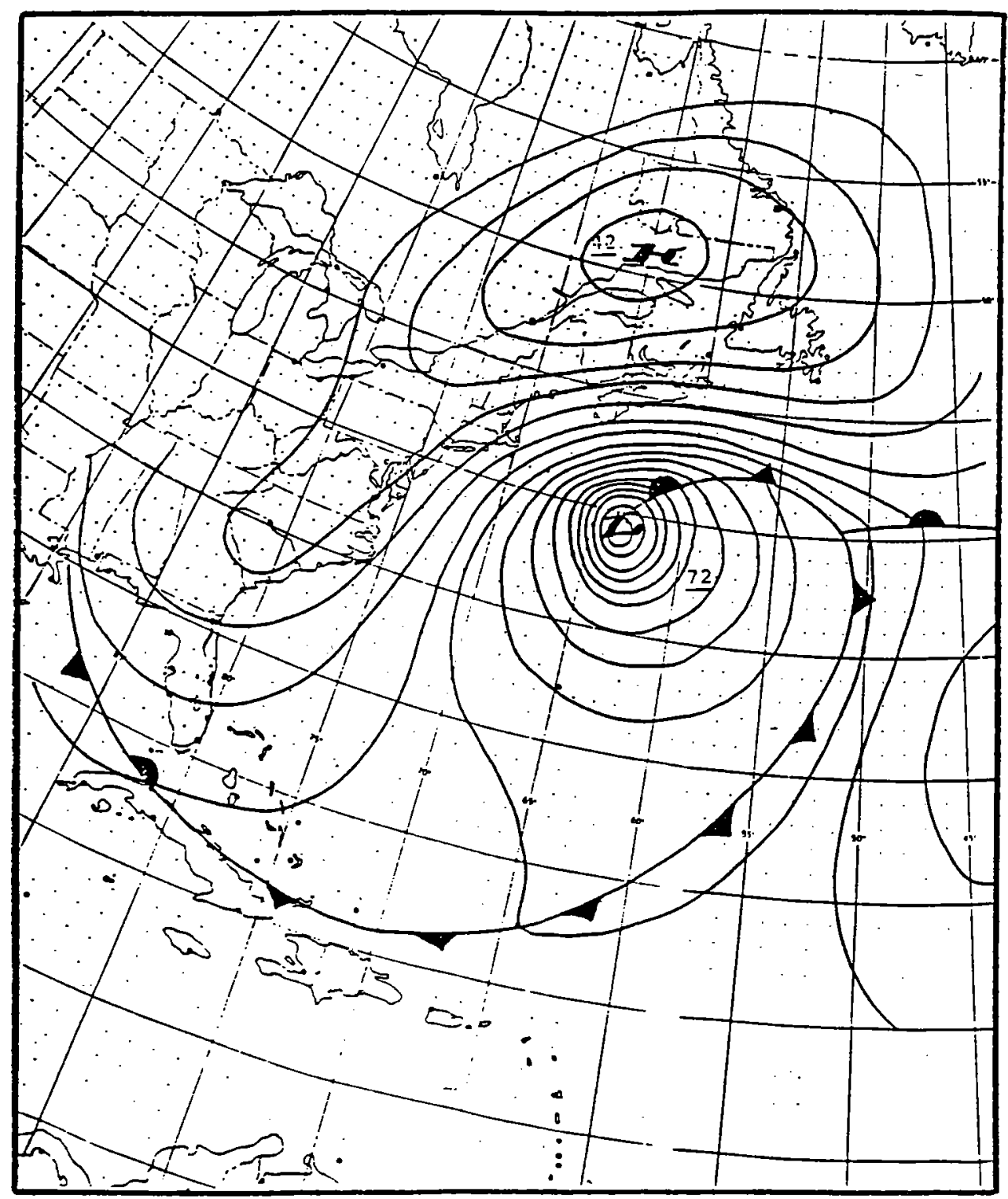

Figure 15. 1200-hr UTC, 30 October 1991, surface analysis

currents, the westward "tilt" (with height) of the trough axis would tend to cause the surface low to move westward.

\section{Thermal Gradient Description}

The presence of a strong anticyclone to the northwest and Hurricane Grace to the southeast of the low which developed into the Halloween Storm, produced an extraordinary temperature gradient for an early season event. The analysis procedures of the thermal conditions present in this event follow those of Neiman and Shapiro (1993) for a similar 1989 event (IOP-4). However, the 


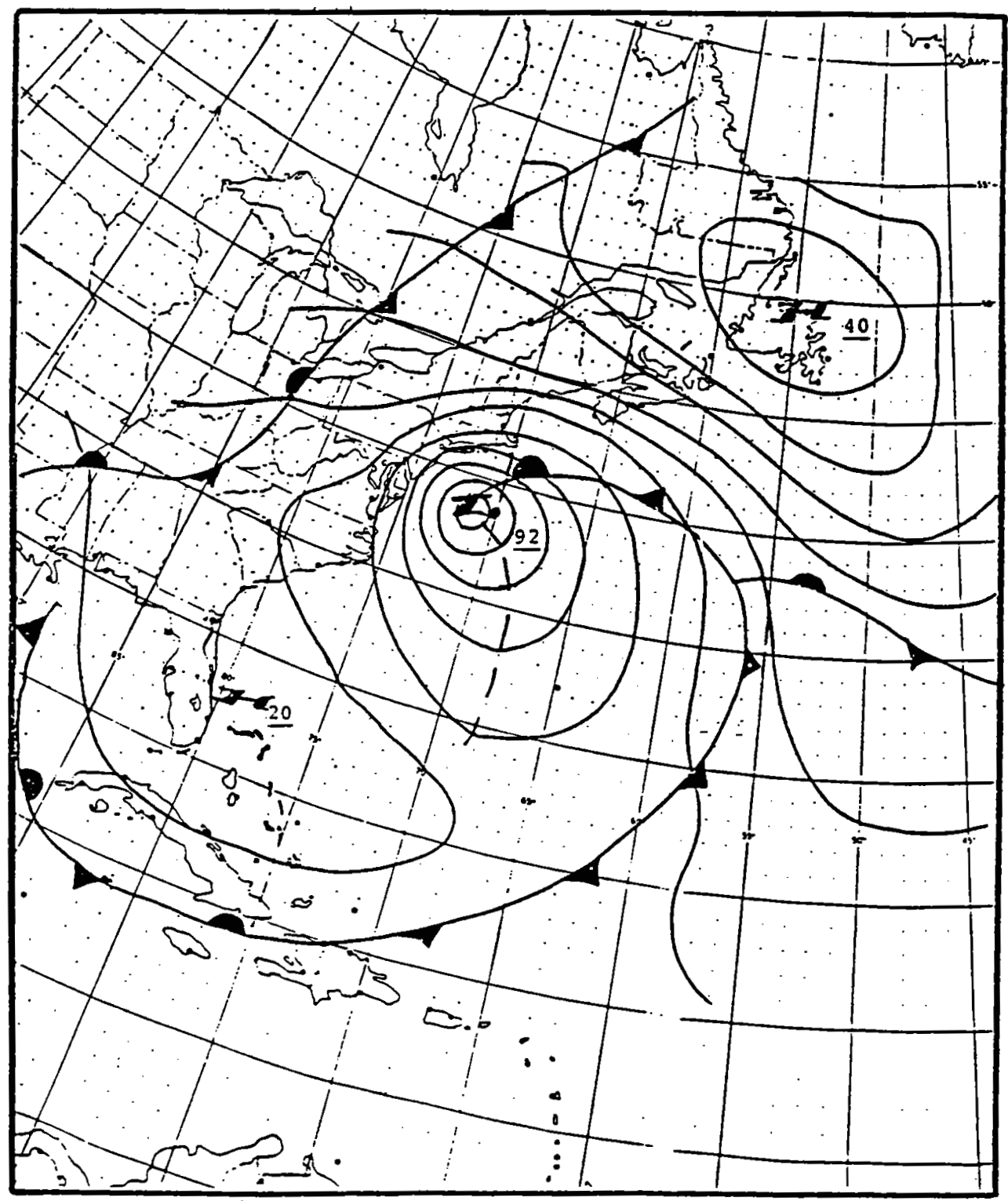

Figure 16. 1200-hr UTC, 31 October 1991, surface analysis

available maps do not permit the level of analysis detail, especially over the marine sector, as for the IOP-4 event discussed by Neiman and Shapiro.

Figures $17-20$ show the 850 -mb temperature $\left({ }^{\circ} \mathrm{C}\right.$ ) fields (approximately 1500-m elevation) over the eastem United States and westem Atlantic at (a) 1200 UTC, 28 October, (b) 0000 UTC, 29 October, (c) 1200 UTC, 29 October, and (d) 0000 UTC, 30 October 1991. 


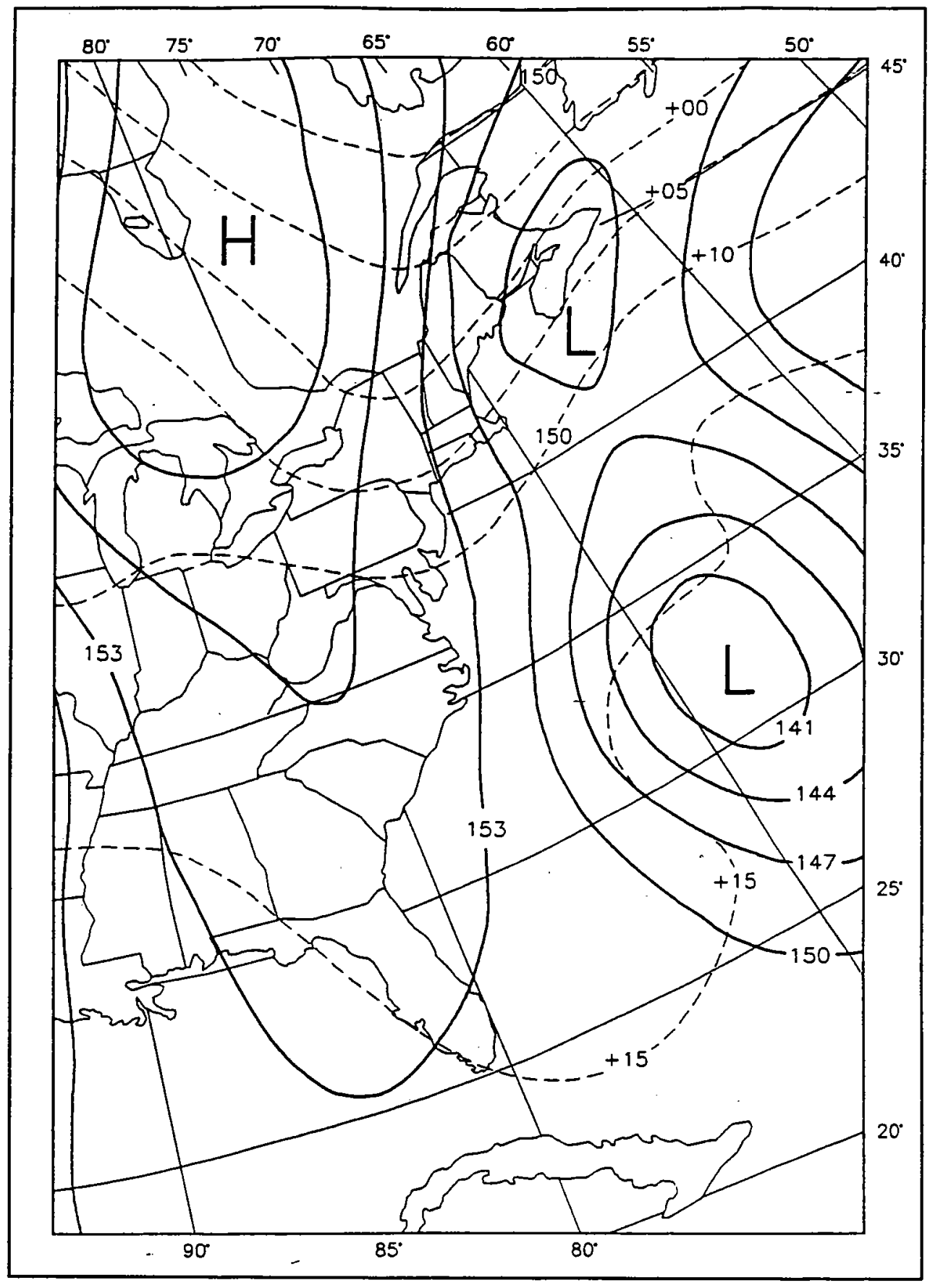

Figure 17. 1200-hr UTC, 28 October 1991, 850-mb height/temperature analysis 


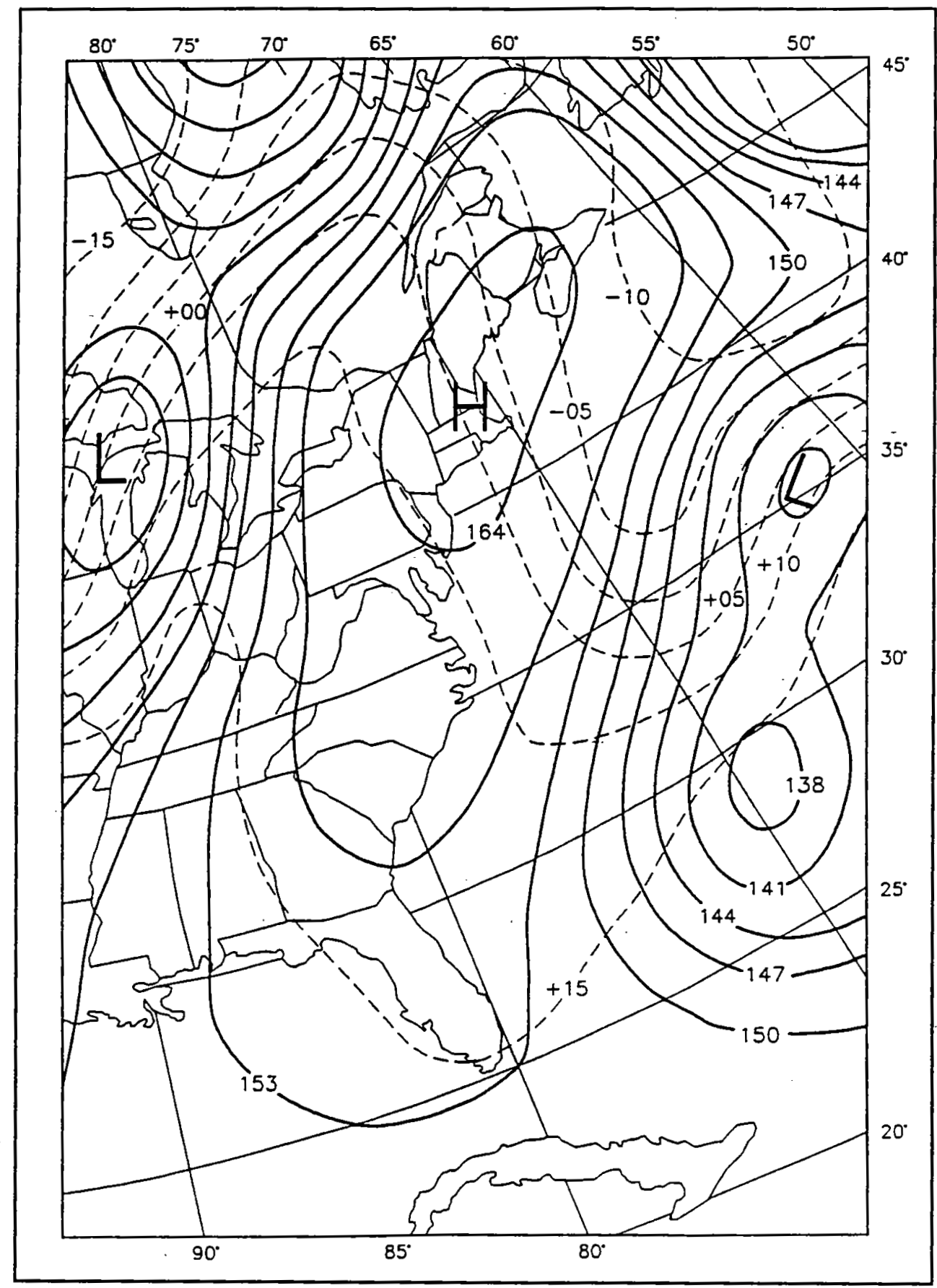

Figure 18. 0000-hr UTC, 29 October 1991, 850-mb height/temperature analysis 


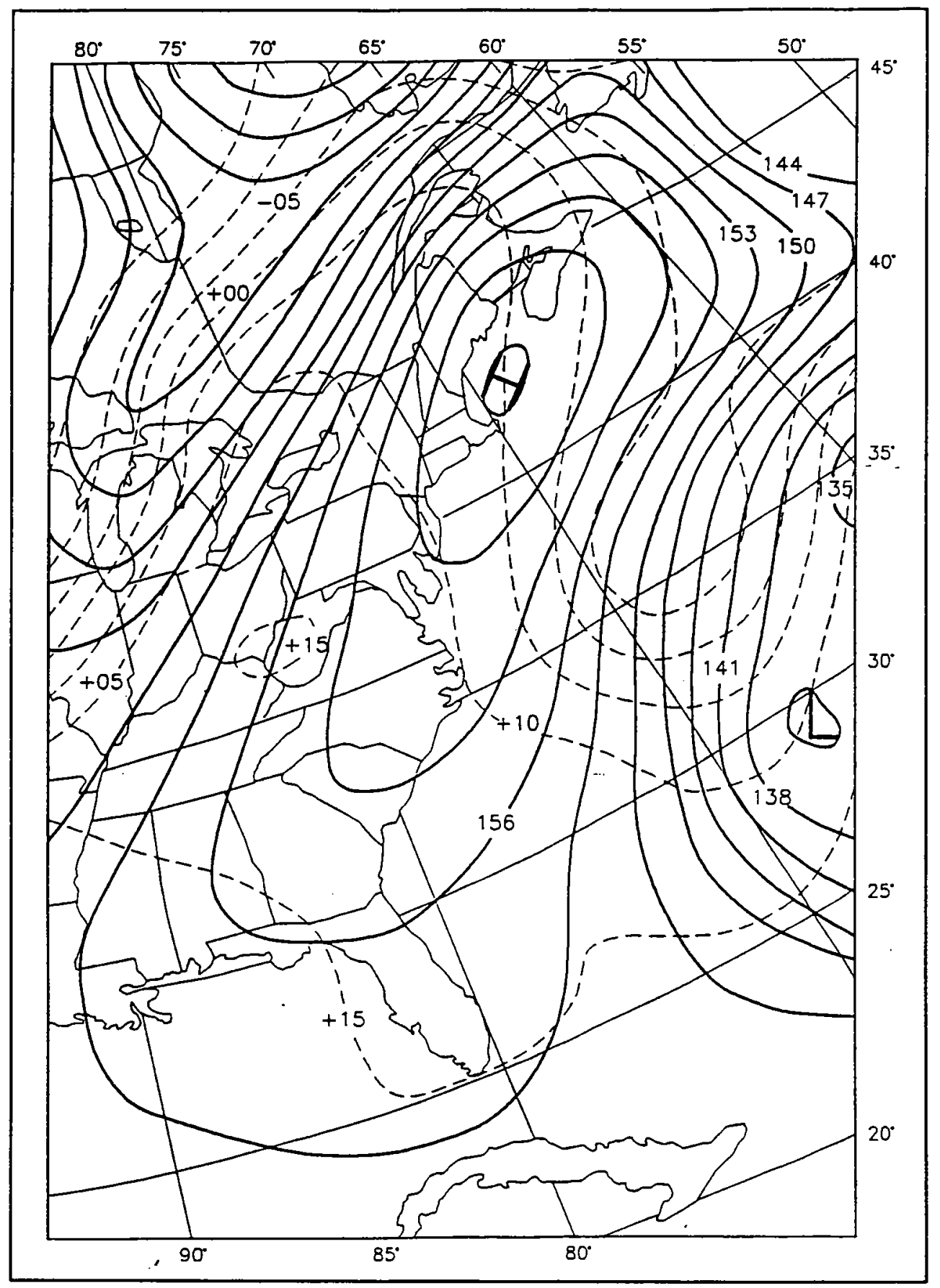

Figure 19. 1200-hr UTC, 29 October 1991, 850-mb height/temperature analysis 


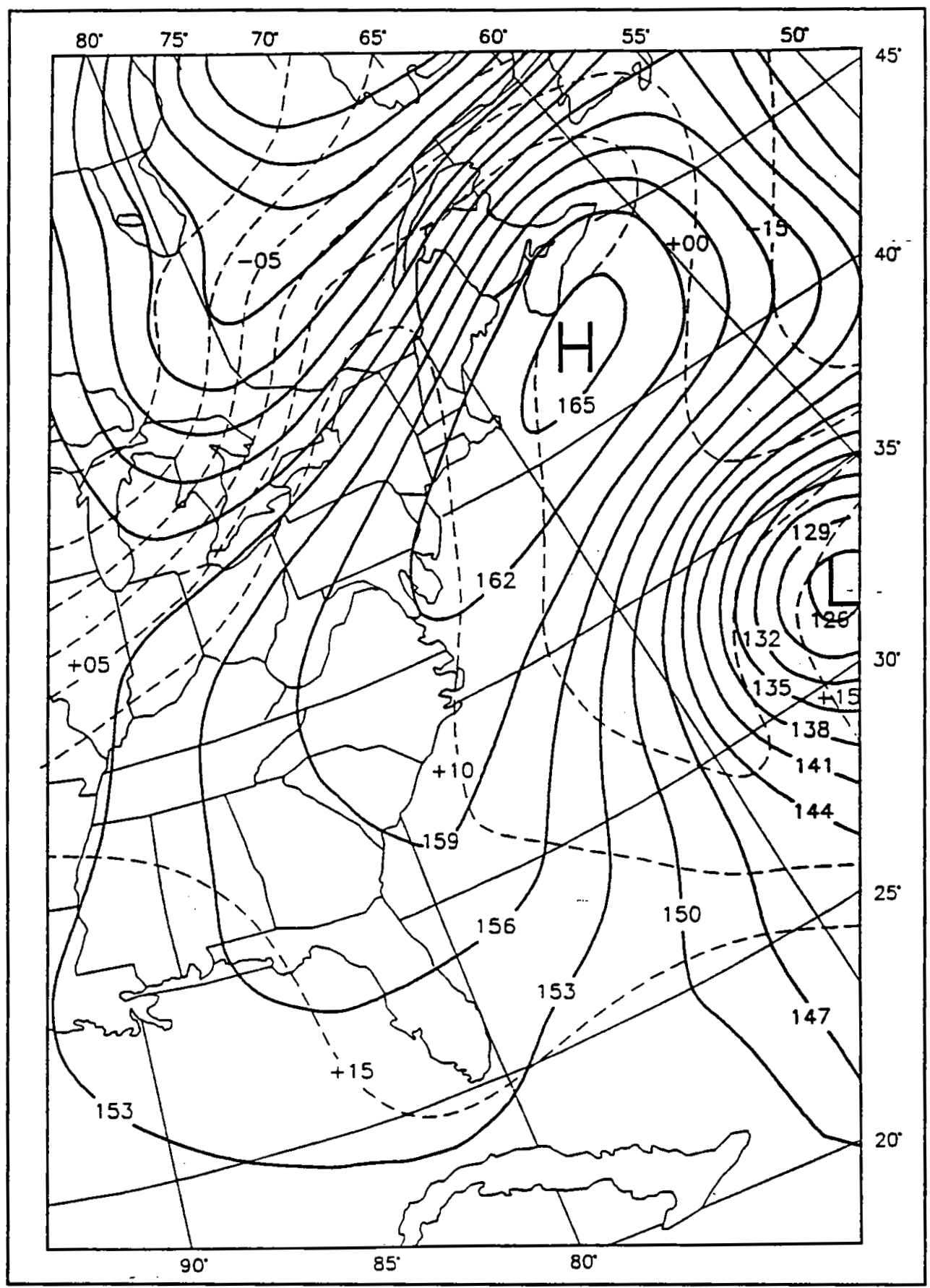

Figure 20. 0000-hr UTC, 30 October 1991, 850-mb height/temperature analysis 


\section{Comparison of Halloween Storm with ERICA IOP-4 Event}

The January 1989 event examined by Neiman and Shapiro (1993) is described by them as one of the most intense cases of extratropical marine cyclone development observed in the western Atlantic geographical region. The IOP -4 event analyzed by Neiman and Shapiro (1993) is the same cited by Pauley and Bramer (1992) and referred to in the previous section of this report. The 850 -mb temperature contrast for that event was approximately $28^{\circ} \mathrm{C}\left(+08^{\circ} \mathrm{C}\right.$ to $\left.-20^{\circ} \mathrm{C}\right)$. The 850 -mb temperature contrast for the Halloween Storm was comparable at $25^{\circ} \mathrm{C}\left(+15^{\circ} \mathrm{C}\right.$ to $\left.-10^{\circ} \mathrm{C}\right)$. The Halloween Storm did not intensify as rapidly as did the IOP -4 event, which deepened at least $60 \mathrm{mb}$ in $24 \mathrm{hr}$ and attained a minimum sea-level pressure of $936 \mathrm{mb}$ and a pressure deficit of at least $80 \mathrm{mb}$ (Nieman, Shapiro, and Fedor 1993). The Halloween Storm deepened only about $40 \mathrm{mb}$ in $48 \mathrm{hr}$, far less than the IOP-4 event. However, the Halloween Storm eventually attained a maximum pressure deficit of $70 \mathrm{mb}$ (NOAA 1992), comparable to that of the IOP-4 event. Moreover, the duration of the Halloween Storm was at least twice as great as that of the IOP -4 event.

While the peak winds of both events were comparable $(25 \mathrm{~m} / \mathrm{s})$, the coastal impact of the IOP-4 event was not significant because of the short duration and because the track resulted in alongshore or offshore wind directions along most reaches of the northern U.S. coastline. At the time of peak storm intensity, the onshore wind directions were confined mostly to coastal Newfoundland. The Halloween Storm is compared to the IOP-4 event because the events are similar and IOP -4 is certainly the best-documented event to occur in a similar geographic region. Even so, there are significant differences, particularly with regard to the presence of Hurricane Grace during the formative stages of the Halloween Storm. Perhaps an objective way to view the influence of Hurricane Grace is not as system-system interaction, but to examine the roles of the strong pressure and temperature gradients in the formation of the Halloween Storm. 


\section{Comparison of Halloween Storm with Blizzard of '78}

The storm of 5-8 February 1978, commonly referred to as the "Blizzard of '78," was, in many respects, similar to the Halloween Storm. Figures 21 through 28 show the surface and 500 -mb analyses at 12-hr intervals starting at $1200 \mathrm{hr}$ UTC, 5 February 1978, and ending at $1200 \mathrm{hr}$ UTC, 8 February 1978 (Fair and Feit 1978). Figure 23, the surface analysis at $1800 \mathrm{hr}$ UTC, 6 February, shows a surface low located just off the northeast coast of the United States and a strong anticyclone $(1,054 \mathrm{mb})$ located near the Hudson Bay region of Canada. Recall that the anticyclone accompanying the Halloween Storm also was located over the Hudson Bay region and reached a maximum surface pressure of $1,046 \mathrm{mb}$.

Concurrently, an upper-level low was located over the eastem Great Lakes, to the west of the surface low, as was the case with the Halloween Storm. One day later at $1200 \mathrm{hr}$ UTC, 7 February (Figure 25), the surface low had drifted slightly to the north but not intensified significantly. The upper level low moved eastward and was co-located with the surface low (Figure 26). At $1200 \mathrm{hr}, 8$ February (Figures 27 and 28), the system intensified, with the surface pressure dropping from $992 \mathrm{mb}$ to $981 \mathrm{mb}$. During the previous day, the system had drifted to the east-northeast, and the upper level and surface lows were still co-located.

Elements common to both the Halloween Storm and the Blizzard of '78 include (a) the presence of a strong anticyclone over the Hudson Bay region of Canada, (b) an upper-level low to the west of the maritime surface low, and (c) strong temperature contrast between the cyclone and anticyclone. In the case of the Blizzard of ' 78 , the temperature difference was $20^{\circ} \mathrm{C}\left(-20^{\circ} \mathrm{C}\right.$ to $-40^{\circ} \mathrm{C}$ ). 


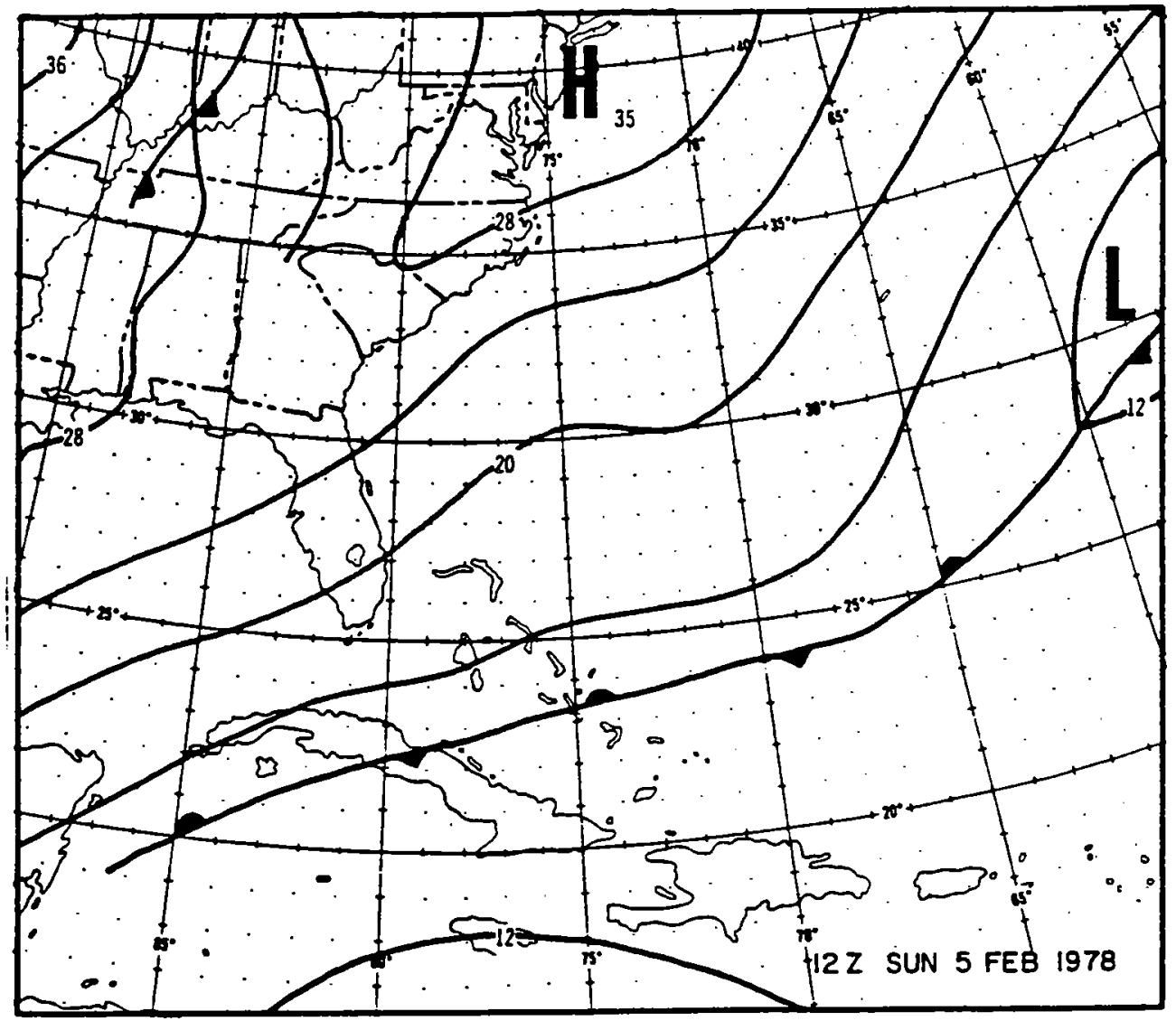

Figure 21. 1200-hr UTC, 5 February 1978, surface analysis 


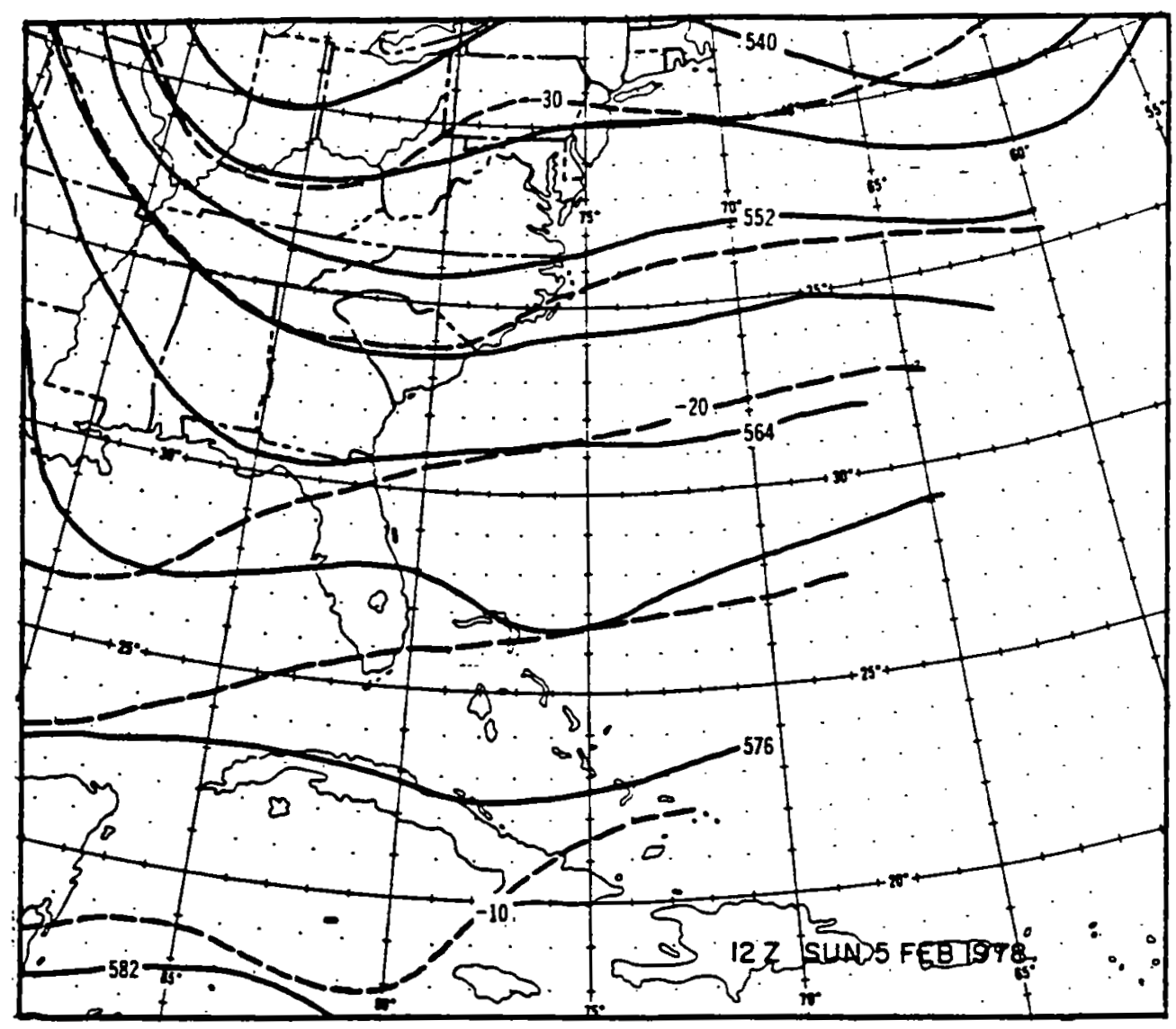

Figure 22. 1200-hr UTC, 5 February 1978, 500-mb height/temperature analysis 


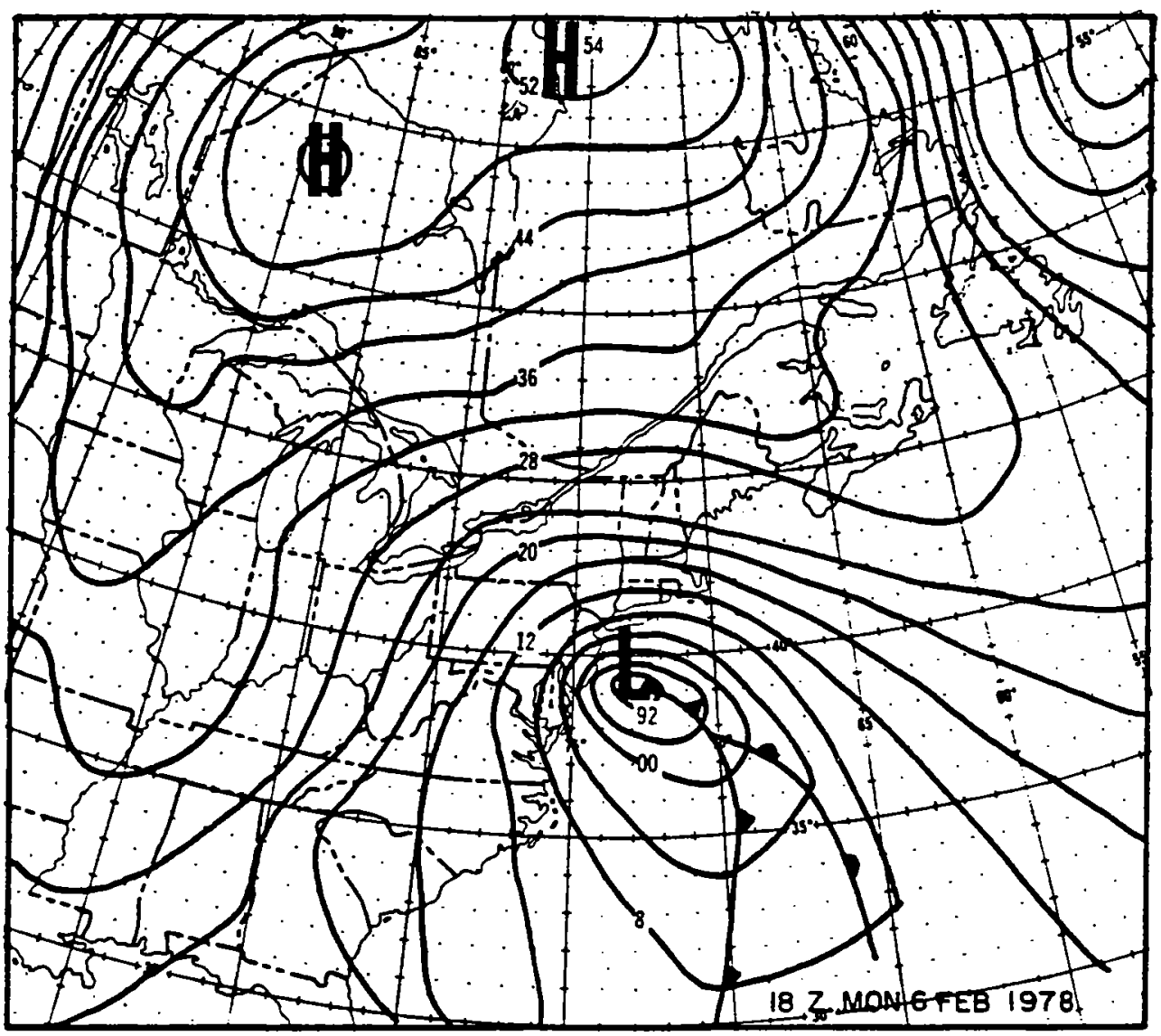

Figure 23. 1800-hr UTC, 6 February 1978, surface analysis 


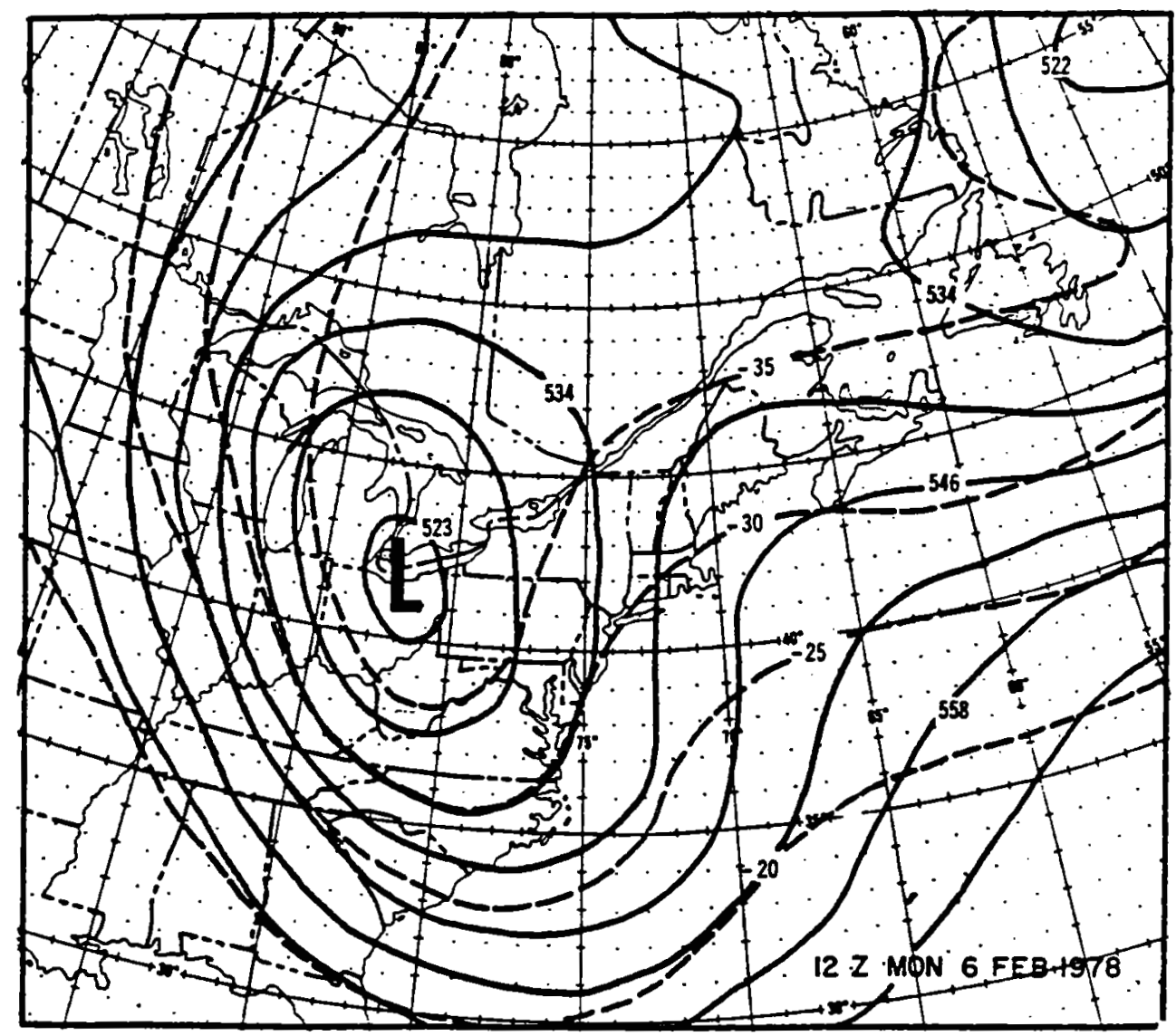

Figure 24. 1200-hr UTC, 6 February 1978, 500-mb heighttemperature analysis 


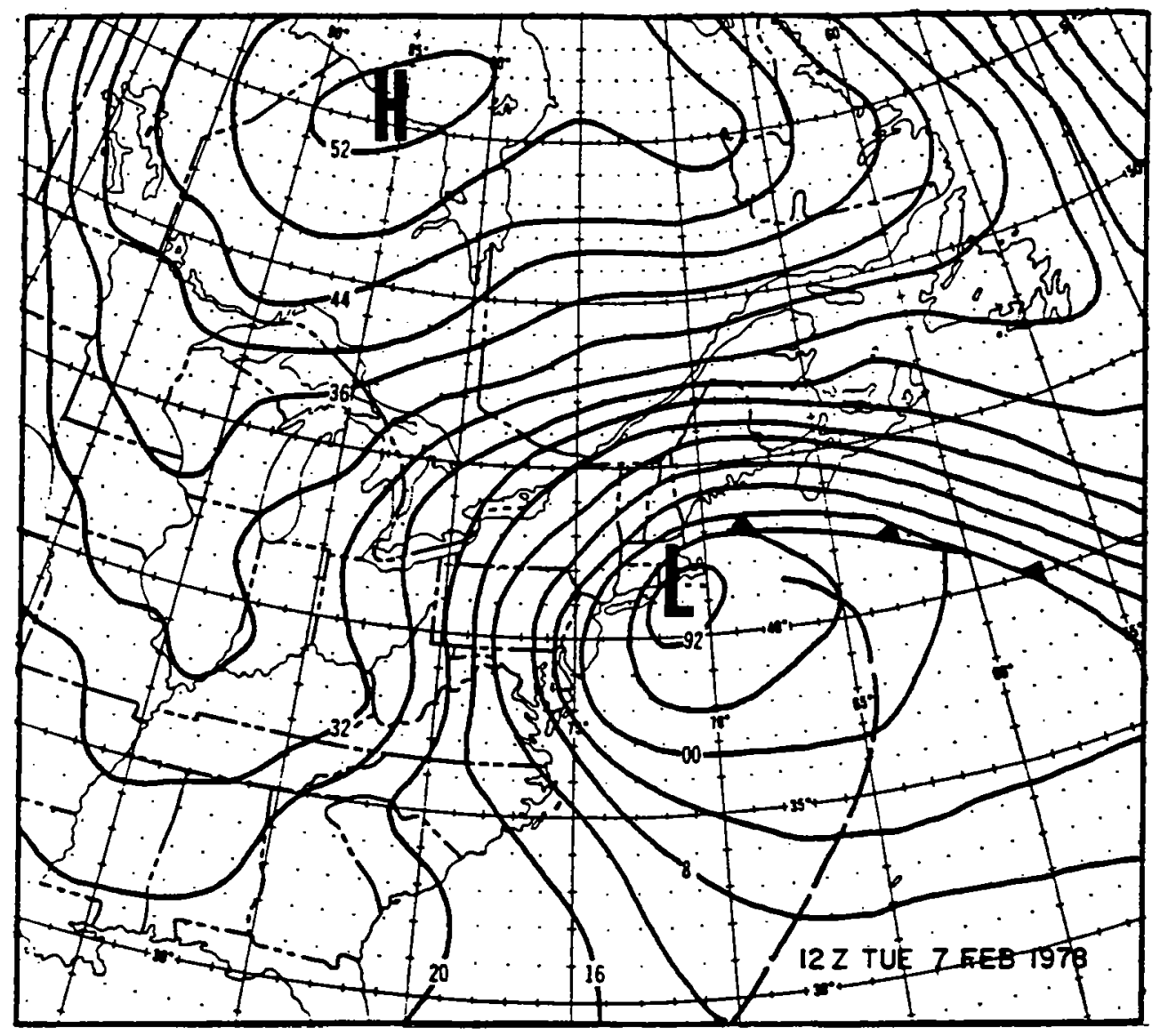

Figure 25. 1200-hr UTC, 7 February 1978, surface analysis 


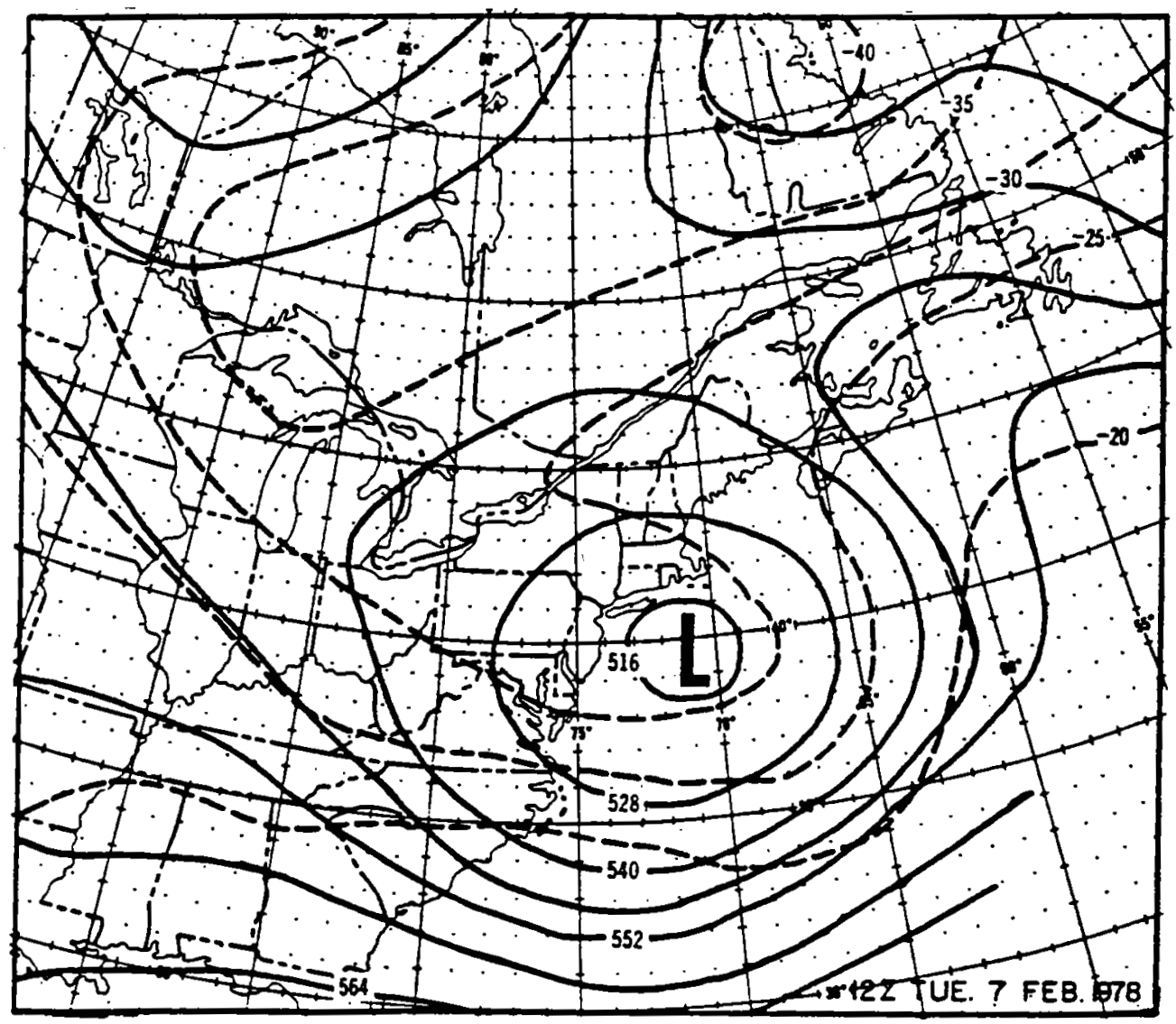

Figure 26. 1200-hr UTC, 7 February 1978, 500-mb height/temperature analysis 


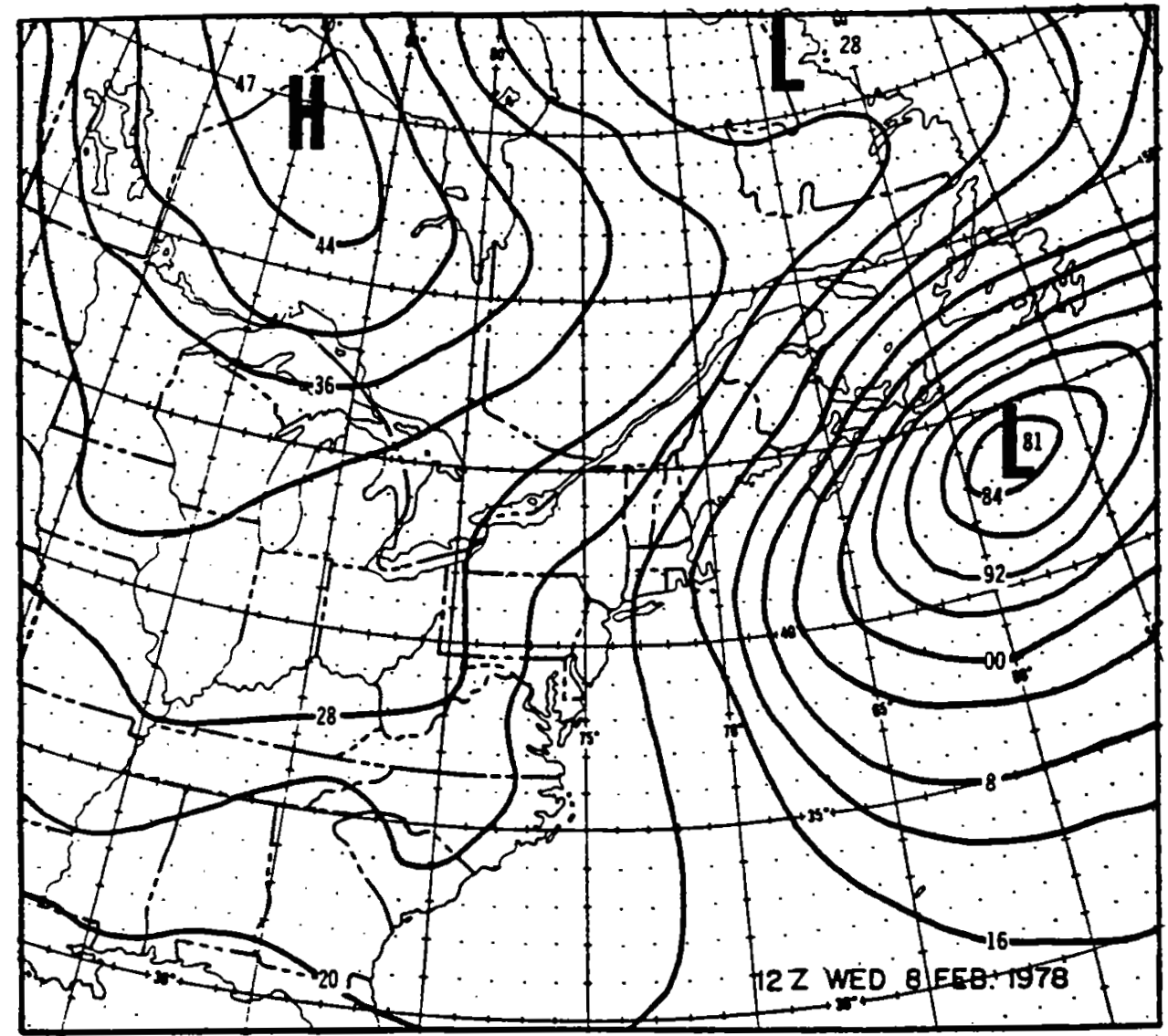

Figure 27. 1200-hr UTC, 8 February 1978, surface analysis 


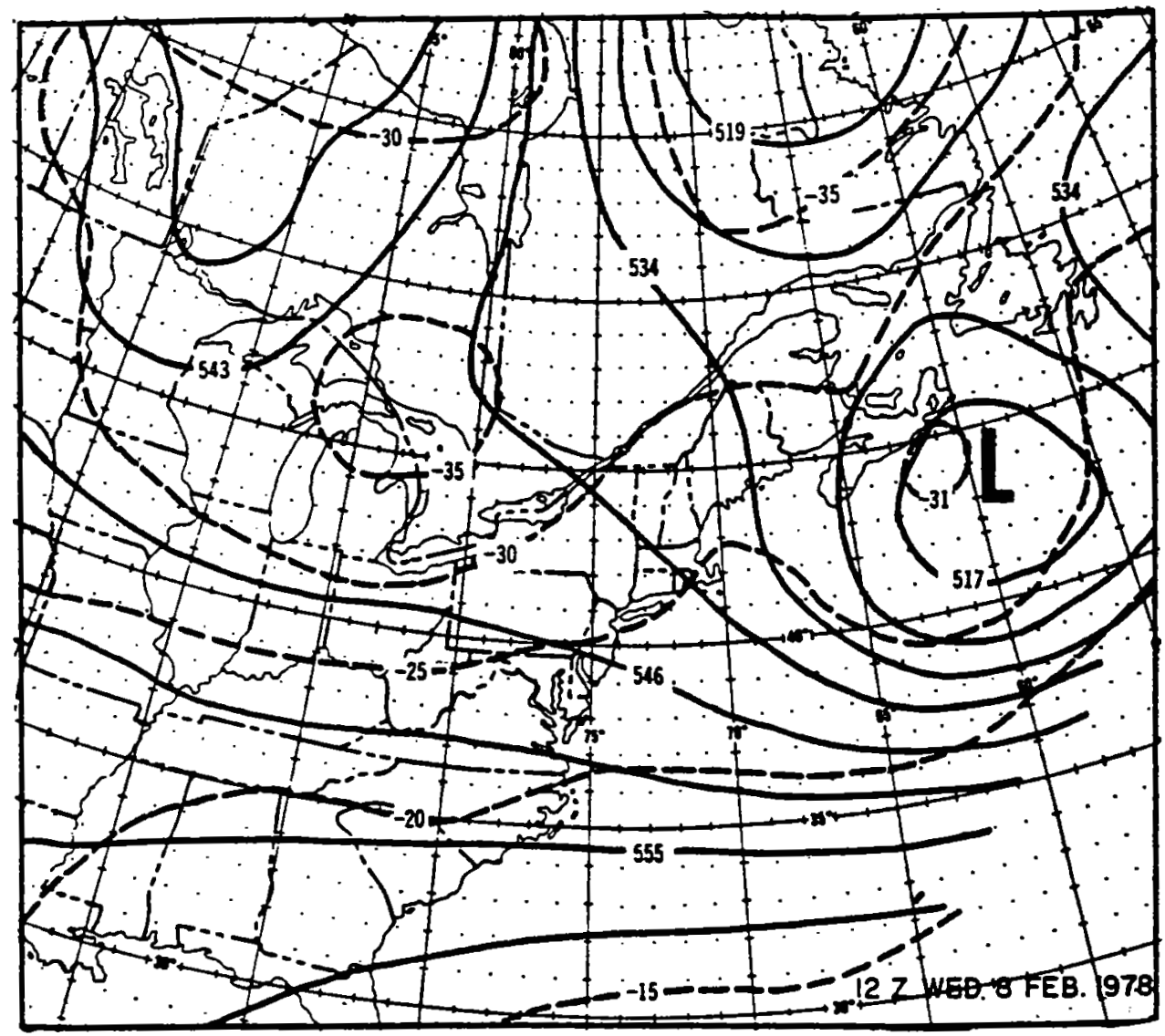

Figure 28. 1200-hr UTC, 8 February 1978, 500-mb height/temperature analysis 


\section{Storm of 4-5 January 1992, Synoptic Analysis}

The meteorological characteristics of the 4-5 January 1992 storm contrast significantly with those of the Halloween Storm. Whereas the Halloween Storm was a large, long-duration, and fairly well-forecast maritime winter cyclone, the 4-5 January storm was a small, rapidly developing, fast-moving event (Jensen and Garcia 1993). Because of the small size and rapid development, it was not well-depicted by the synoptic analysis products and therefore not well-forecast. ${ }^{1}$ Based upon radar imagery data, the center of the storm made landfall about $40 \mathrm{~km}$ ( 25 miles) south of Ocean City, MD.

Because of the small size of the storm, coastal effects did not extend much beyond the Delaware Bay to the north. Based upon Doppler radar data, the Ocean City area probably was within the highest coastal wind zone. Unfortunately, no wind data are known to have been acquired at Ocean City. However, an anemometer operated by the National Park Service on Assateague Island was located approximately $30 \mathrm{~km}$ south of Ocean City. Figure 29 shows the wind speed, direction, and barometric pressure data acquired at Assateague Island during the storm. The sudden drop in barometric pressure to $951 \mathrm{mb}$ at about $2000 \mathrm{hr}$ EST is a spurious data point. Note that the wind direction at the storm peak was about 90 deg or directly from the east.

Infrared imagery obtained by the GOES satellite was examined for the 24-hr period prior to the storm's landfall on the Delmarva Peninsula at approximately $1200 \mathrm{hr}$ UTC, 4 January 1992 . Visual signs of incipient storm formation are not apparent until $0000 \mathrm{hr}$ UTC, 4 January 1992 . By $0600 \mathrm{hr}$ UTC, 4 January, the system was well-formed with a visual center located about 150 miles due east of Cape Hatteras. At $1200 \mathrm{hr}$ UTC, 4 January the storm appeared better developed than at $0600 \mathrm{hr}$ and the visual center was very near the Delmarva Peninsula coastline. Based upon satellite imagery, it appears the system did not become well-organized until between $0000 \mathrm{hr}$ UTC and $0600 \mathrm{hr}$ UTC, 4 January 1992. Surface wind data (Figures 30 and 31) obtained at National Data Buoy Center (NDBC) buoys 44009 and 44012 tend to support this conclusion.

1 Personal Communication. (1992). J. Belville, National Weather Service, Sterling, VA. 


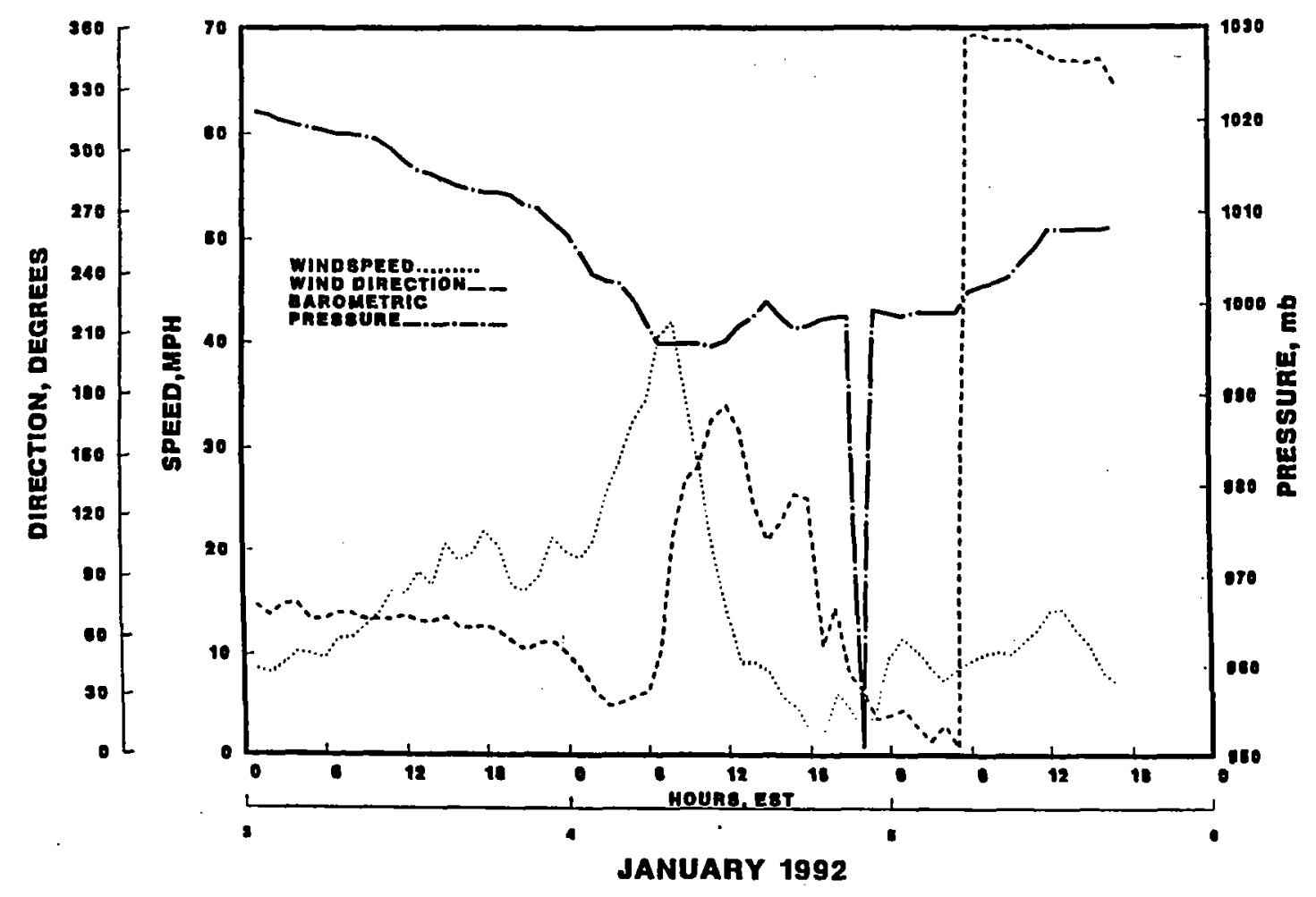

Figure 29. Wind and surface pressure data from National Park Service meteorological station on Assateague Island during 4-5 January 1992 storm

Figure 32 is a 1220 UTC, 4 January 1992 surface pressure analysis of the event provided by the NWS Forecast Office at Sterling, VA. The minimum surface pressure indicated on the analysis is $994 \mathrm{mb}$. The actual pressure may have been slightly lower, between 990 and $992 \mathrm{mb}^{1}$ Note that the outermost closed isobar $(1,000 \mathrm{mb})$ is of relatively small radius, about $200 \mathrm{~km}$. The $200-\mathrm{km}$ radius definitely places it in the small, short-lived cyclone category as defined by Nielsen and Dole (1992). By $1800 \mathrm{hr}$ UTC, 4 January, radar indicated the system had moved across the Chesapeake Bay into Virginia and begun to dissipate.

The 4 January event occurred in a geographic area that was populated by offshore meteorological buoys, was within the range of an advanced weather radar (NWS WSR88-D, Sterling, VA), and caused significant damage to a limited coastal area. Nonetheless, the event was not well-documented. The short duration of the 4 January storm, from approximately $1800 \mathrm{hr}$ UTC, 3 January to $1800 \mathrm{hr}$ UTC, 4 January 1992, and small size (about $500 \mathrm{~km}$ across), fall within the size and duration range that are poorly depicted in operational analyses based upon the studies described in Chapter 2. This finding is consistent with the fact that the storm was not well-forecast. The poor

1 Personal Communication. (1992). V. Thompson, National Weather Service. 


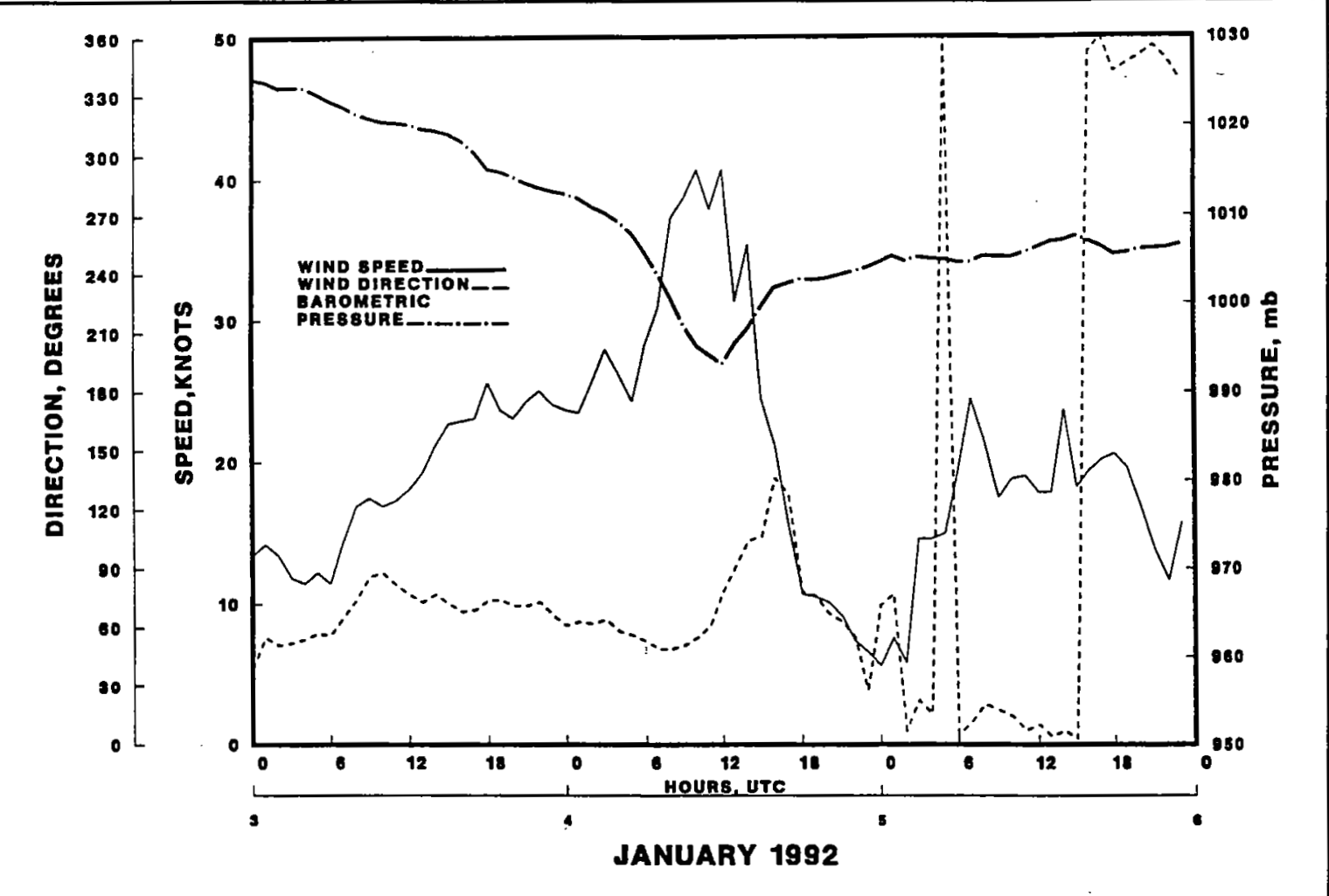

Figure 30. Surface wind data at NDBC buoy 44009 during 4-5 January 1992 storm

analysis depiction of this event makes it doubtful that an event of similar size, duration, and intensity, but occurring in an open-ocean geographic region, would be correctly identified and characterized. 


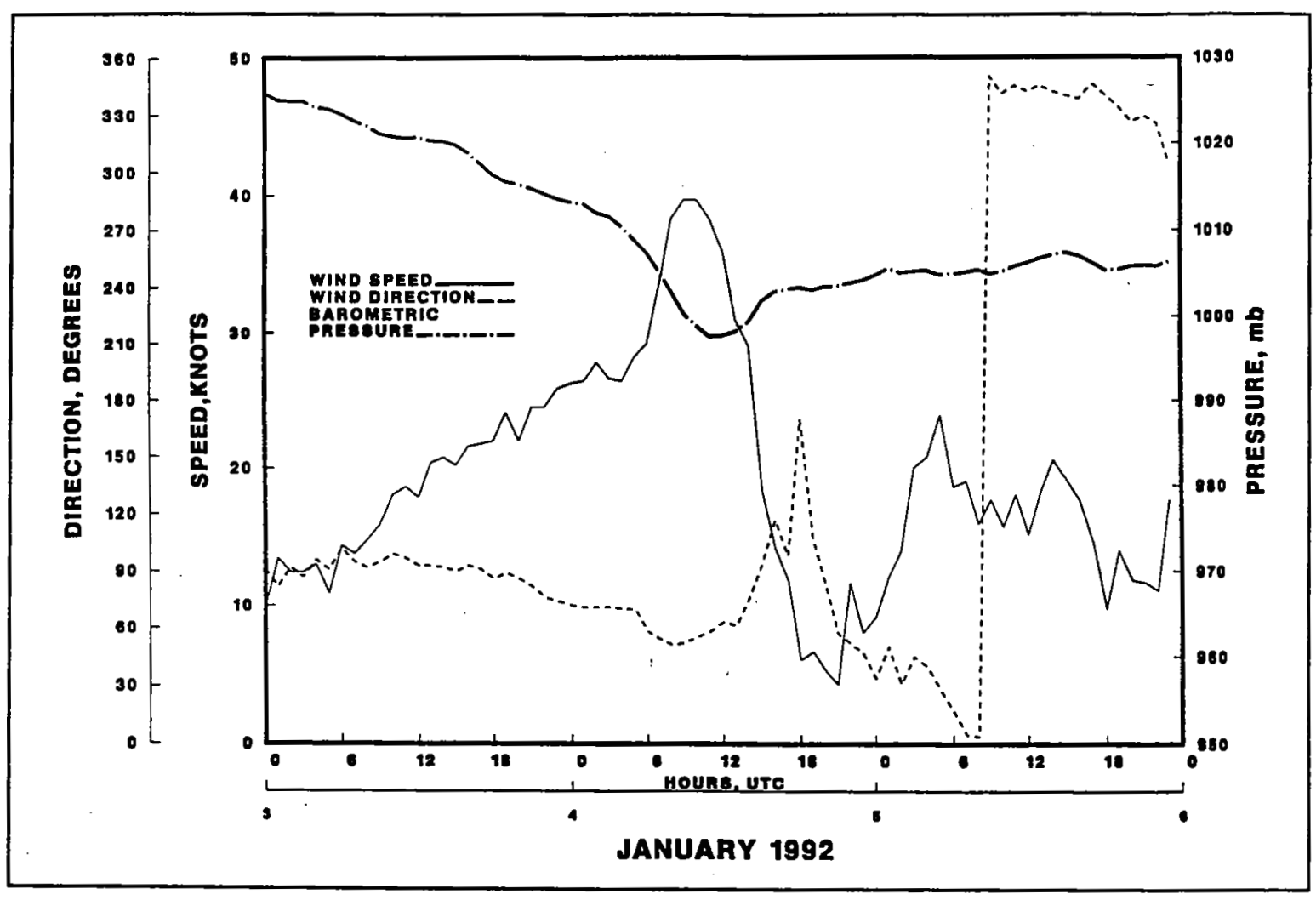

Figure 31. Surface wind data at NDBC buoy 44012 during 4-5 January 1992 storm 


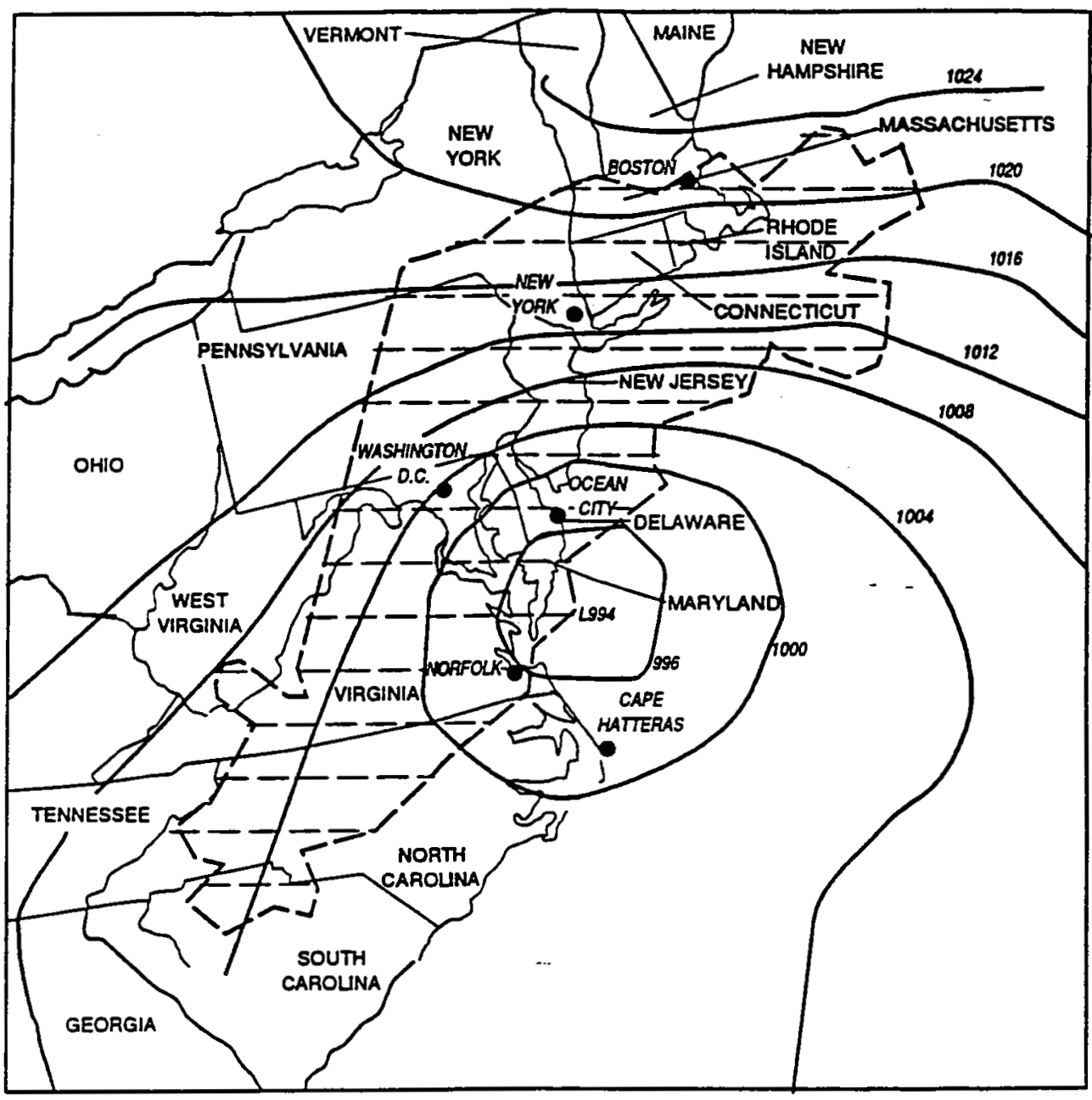

Figure 32. 1220-hr UTC, 4 January 1992, surface pressure analysis 


\section{Western Atlantic Retrograde Storms}

An initial step to estimate the frequency of occurrence of a storm having characteristics similar to those of the Halloween Storm was to focus on westem Atlantic storms exhibiting retrograde (movement east to west) tracks. This characteristic of the Halloween Storm is an obvious one and is readily and objectively determined. Moreover, using this characteristic minimizes the effect of incorrect depiction in the analysis products of other commonly used storm characterization parameters. The Mariners Weather Log was examined for northwestem Atlantic storms that occurred from 1956 to 1991 with retrograde tracks. The domain of examination was west of longitude $50^{\circ} \mathrm{W}$ and south of latitude $55^{\circ} \mathrm{N}$. Storms are tabulated by month and year of occurrence.

Table 3 summarizes the tabulations. There were 111 storms exhibiting retrograde tracks during the 34 -year period, or an average of 3.2 retrograde storms per year. The number of retrograde storms in any 1 year ranged from 0 (1973 and 1981) to 9 (1958). There does not appear to be any particular year-to-year correlation. There does appear to have been significantly fewer storms (21) in the most recent decade, 1980-1989, than in the two previous decades, 35 storms in the 1970-1979 decade and 37 storms in the 1960-1969 decade.

The annual distribution, presented in Figure 33, shows a pronounced seasonal variation with more storms occurring in the fall-winter months, as expected. However, the fall-winter distribution appears bimodal with peaks in November (12) and April (14). The statistical significance of this bimodality is questionable given the small sample size. The greatest inter-month difference occurs between October (6) and November (12), which suggests that the strong thermal contrast which occurs when cold continental air masses move south to meet the warmer subtropical maritime air is a significant contributor to the formation of systems which may take retrograde tracks. 


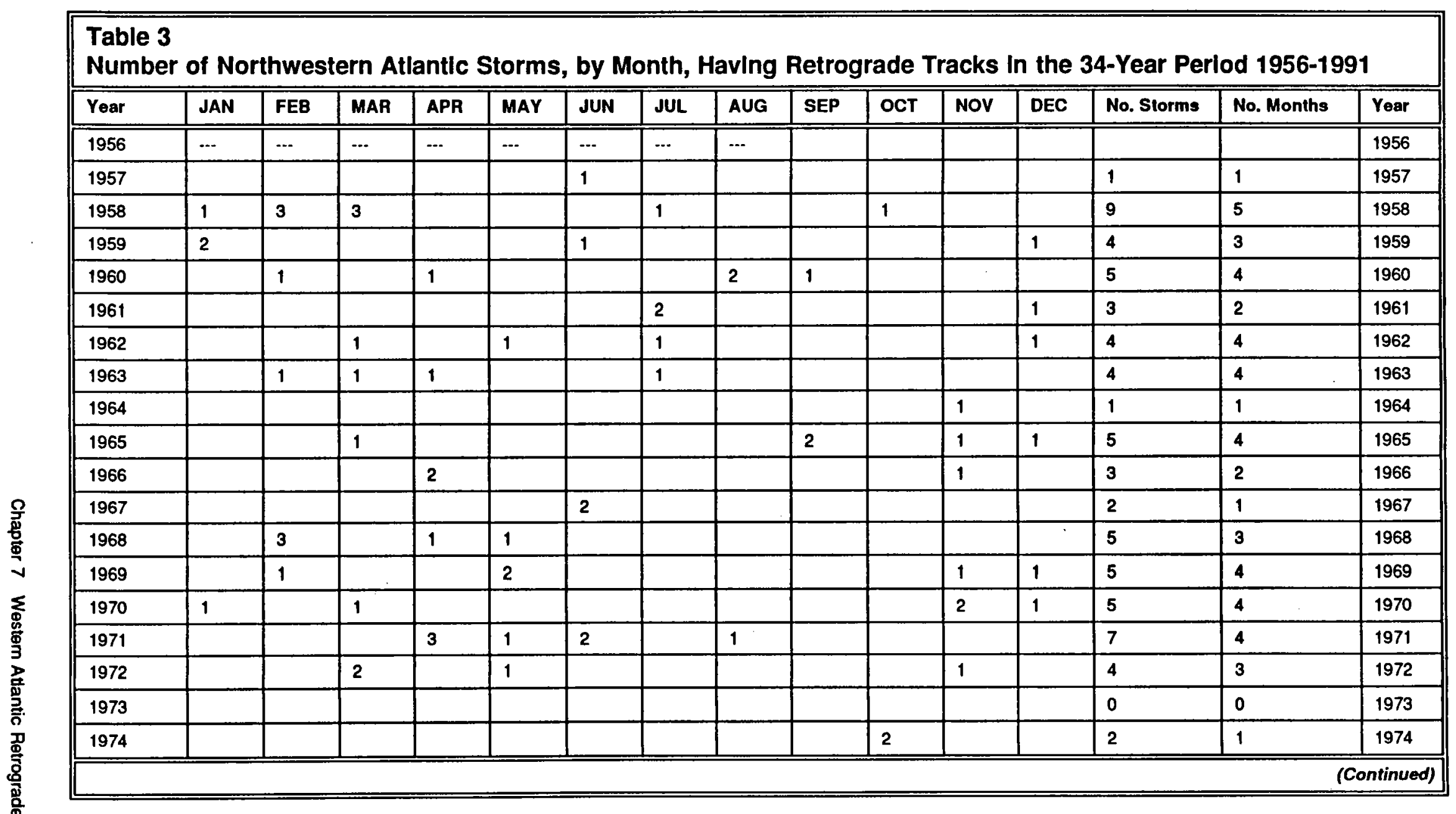




\begin{tabular}{|c|c|c|c|c|c|c|c|c|c|c|c|c|c|c|c|}
\hline Year & JAN & FEB & MAR & APR & MAY & JUN & JUL & AUG & SEP & OCT & Nov & DEC & No. Storms & No. Months & Year \\
\hline 1975 & & & & & & 1 & & 1 & & & & & 2 & 2 & 1975 \\
\hline 1976 & & & & & & & & 1 & & & 1 & & 2 & 2 & 1976 \\
\hline 1977 & 2 & & & & & & & & & & 2 & & 4 & 2 & 1977 \\
\hline 1978 & & 2 & & 1 & & & & & & & & & 3 & 2 & 1978 \\
\hline 1979 & 1 & 1 & & & 1 & 1 & & & 1 & 1 & & & 6 & 6 & 1979 \\
\hline 1980 & 1 & & & & 1 & & 1 & & & & & 1 & 4 & 4 & 1980 \\
\hline 1981 & & & & & & & & & & & & & 0 & 0 & 1981 \\
\hline 1982 & & & & & & & & & & & 1 & & 1 & 1 & 1982 \\
\hline 1983 & & & & 1 & & & 1 & & 1 & & & & 3 & 3 & 1983 \\
\hline 1984 & & & 1 & & & & & & & & 1 & & 2 & 2 & 1984 \\
\hline $1985 \cdot$ & & 1 & & 2 & & & & & & & & & 3 & 2 & 1985 \\
\hline 1986 & & & & 1 & & & & & 1 & & & & 2 & 2 & 1986 \\
\hline 1987 & & & & 1 & & & & & & & & & 1 & 1 & 1987 \\
\hline 1988 & & & & & & & 1 & & & & & & 1 & 1 & 1988 \\
\hline 1989 & & & & & 2 & & & & & 1 & & 1 & 4 & 3 & 1989 \\
\hline 1990 & & & & & & 1 & & 1 & & 1 & & & 3 & 3 & 1990 \\
\hline 1991 & & & & & & 1 & $\cdots$ & $-\cdots$ & --- & $\ldots$ & -- & $\ldots$ & & & \\
\hline Tot. Stms. & 8 & 13 & 10 & 14 & 10 & 10 & 8 & 6 & 6 & 6 & 12 & 8 & 111 & & \\
\hline Stm. Yrs. & 6 & 8 & 7 & 10 & 8 & 8 & 7 & 5 & 5 & 5 & 10 & 8 & 87 & & \\
\hline
\end{tabular}




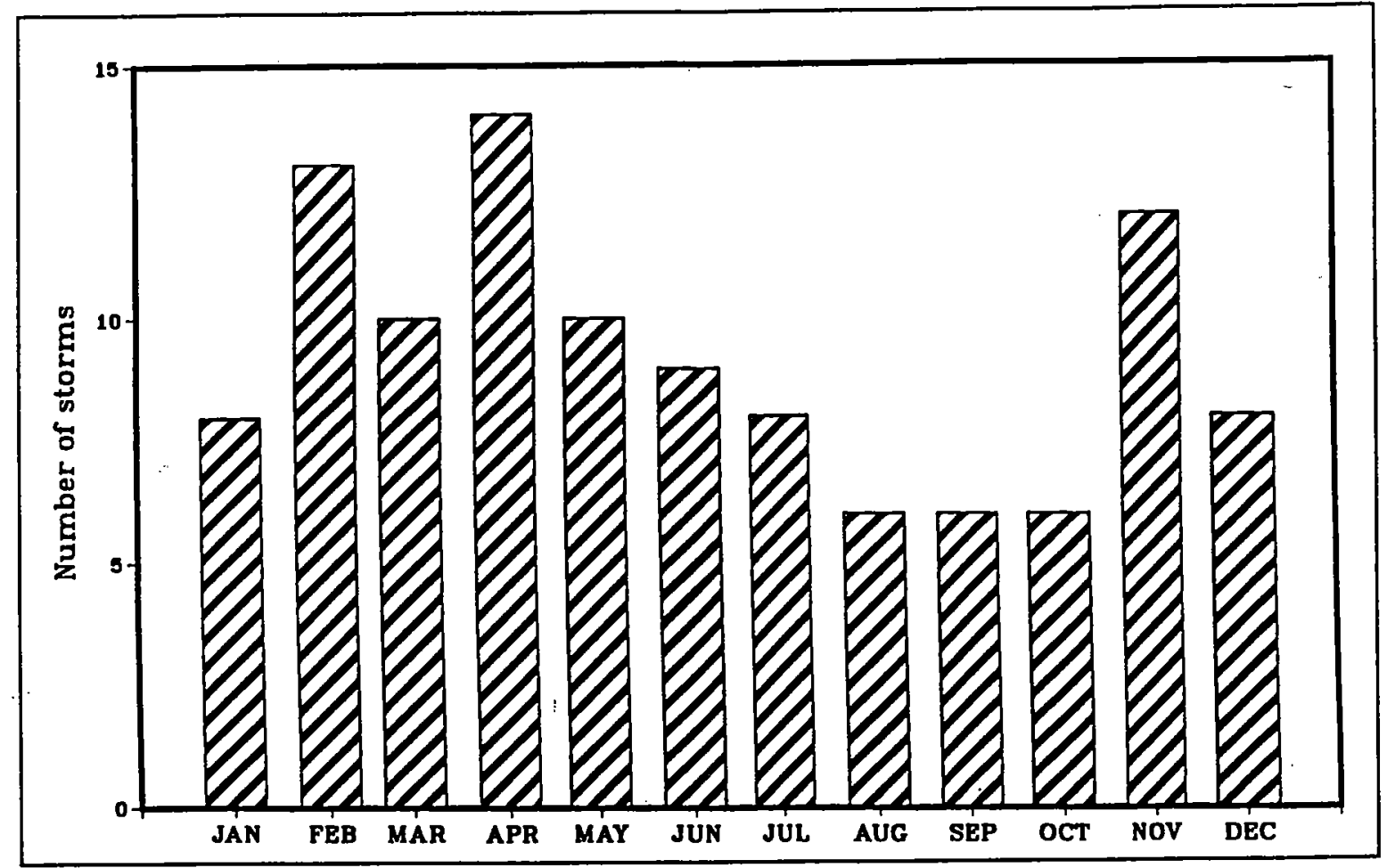

Figure 33. Average annual distribution of northwestem Atlantic storms with retrograde tracks, 1956-1991 


\section{Summary and Conclusions}

The primary focus of this report is the determination of meteorological factors which can be used to identify the population of storms similar to the Halloween Storm and the storm of 4-5 January 1992. Identification of these populations is necessary in order to arrive at a determination of frequency of occurrence. The limitations and possible consequences of relying upon commonly available operational analyses for identifying and selecting candidate events to include in these populations have been presented and discussed. A synoptic analysis of the Halloween Storm is included and the storms is compared with two similar events, one of which (the ERICA IOP-4 event) was extremely well-documented. Meteorological factors which appear common to all three events have been cited. The factors are based upon both observations and theoretical investigations. A synoptic analysis of the 4-5 January 1992 storm which affected Ocean City, MD, also is presented.

The following conclusions have been reached regarding factors affecting the occurrence of storms similar to the Halloween Storm. It has been shown that the values of at least two of the factors used to identify this type of storm, (size and intensity as measured by the minimum central pressure) are dependent upon the depiction of the events. Given the sparse data typical of the marine environment, it may not always be possible to retrieve an accurate estimate of these factors for every candidate event. Moreover, it appears probable that certain pre-existing conditions are necessary for the formation of large, long-duration, Halloween Storm-like events regardless of the subsequent track the system may take. Common characteristics involved in the formation and duration of Halloween Storm-like events appear to be:

a. The presence of a strong anticyclone in the vicinity of the Hudson Bay region of Canada.

b. The presence of strong temperature contrast $\left(20^{\circ} \mathrm{C}\right.$ or greater) between the Canadian anticyclone and the maritime surface low at both the surface and mid-troposphere levels.

c. The presence of a mid- to upper-level low to the west of the maritime surface low, typically over the Great Lakes region of the United States during the early (formative) stages of the event. 
d. A period of prolonged ( $>24 \mathrm{hr}$ ) deepening; while the Halloween Storm did not meet the explosive deepening criterion $(18 \mathrm{mb} / 24 \mathrm{hr}$ at latitude $40^{\circ}$ ) of Sanders and Gyakum (1980), it did deepen at a rate equivalent to $15 \mathrm{mb} / 24 \mathrm{hr}$ for $48 \mathrm{hr}$.

In addition to the above conclusions, it also may be inferred that there has been a significant decline in the number of retrograde storms in the 1980-1989 decade as compared with the two previous decades ( 21 versus 36 average). However, this may not be a statistically valid conclusion given the relatively short history we have assembled.

Conclusions concerning determination of occurrence frequency for small, rapidly intensifying storms such as the 4-5 January 1992 event will be difficult to draw because of the inability of the synoptic weather products to adequately depict these events. This makes the parent population of these storms difficult to identify.

Recommendations include developing a method to compensate for the apparent bias toward higher central pressures, smaller size, and shorter duration derived from operational analysis depictions. In addition, vorticity fields, in addition to the height and temperature fields, may provide additional support to the tentative conclusions drawn and additional insight to the event development process. 


\section{References}

Bleck, R. (1990). "Depiction of upper/lower vortex interaction associated with extratropical cyclogenesis," Mon. Wea. Rev 118, 573-585.

Davis, C. A., and Emanuel, K. A. (1988). "Observational evidence for the influence of surface heat fluxes on rapid maritime cyclogenesis," Mon. Wea. Rev. 118, 2,649-2,659.

Fair, T., and Feit, D. M. (1978). "The Blizzard of '78," Mar. Wea. Log 22, 255-260.

Gyakum, J. R. (1983). "On the evolution of the QE-II storm: Synoptic aspects," Mon. Wea. Rev. 111, 1,137-1,155.

Hadlock, R., and Krietzberg, C. W. (1988). "The experiment of rapidly intensifying cyclones over the Atlantic (ERICA) field study: Objectives and plans," Bull. Amer. Met. Soc. 69, 1,309-1,320.

Hoskins, B. J., McIntyre, M. E., and Robertson, A. W. (1985). "On the use and significance of isentropic potential vorticity maps," Quart. J. Royal Meteor. Soc. 111, 877-946.

Jensen, R. E., and Garcia, A. W. (1993). Wind, wave, and water level assessments for the January 4, 1992 storm at Ocean City, Maryland," Shore and Beach 61, 13-22.

Krietzberg, C. W. (1991). "Mesoscale phenomena in winter cyclones," U.S. Nat. Rep. to IGU, 1987-1990, Rev. Geophy., 98-103.

National Oceanic and Atmospheric Administration. (1992). "National Disaster Survey Report: The Halloween Nor'easter of 1991 - East Coast of the United States...Maine to Florida and Puerto Rico, October 28 to November 1, 1991." Department of Commerce, Washington, DC.

Nielson, J. W., and Dole, R. M. (1992). "A survey of extratropical cyclone characteristics during GALE," Mon. Wea. Rev. 120, 1,156-1,167. 
Neiman, P. J., and Shapiro, M. A. (1993). "The life cycle of an extratropical marine cyclone; Part I: Frontal-cyclone evolution and thermodynamic air-sea interaction," Mon. Wea. Rev. 121, 2,153-2,176.

Neiman, P. J., Shapiro, M. A., and Fedor, L. S. (1993). "The life cycle of an extratropical marine cyclone; Part II: Mesoscale structure and dynamics," Mon. Wea. Rev. 121, 2,177-2,199.

Palmen, E., and Newton, C. W. (1969). "Atmospheric circulation systems Their structure and physical interpretation." Academic Press, New York.

Pauley, P. M., and Bramer, B. J. (1992). "The effects of resolution on the depiction of central pressure for an intense oceanic extratropical cyclone," Mon. Wea. Rev. 120, 757-769.

Sanders, F. (1990). "Surface analysis over the oceans - searching for sea truth," Wea. Forecasting 5, 596-612.

Sanders, F., and Gyakum, J. R. (1980). "Synoptic-dynamic climatology of the bomb," Mon. Wea. Rev. 108, 1,589-1,606.

Silberberg, S., and Bosart, L. F. (1982). "An analysis of systematic cyclone forecast errors in the NMC LFM-II model during the 1978-79 cool season," Mon. Wea. Rev. 110, 254-271.

Weinstein, A. I., and Sanders, F. (1989). "Wind increases in rapid marine cyclogenesis," Mon. Wea. Rev. 117, 1,365-1,367. 


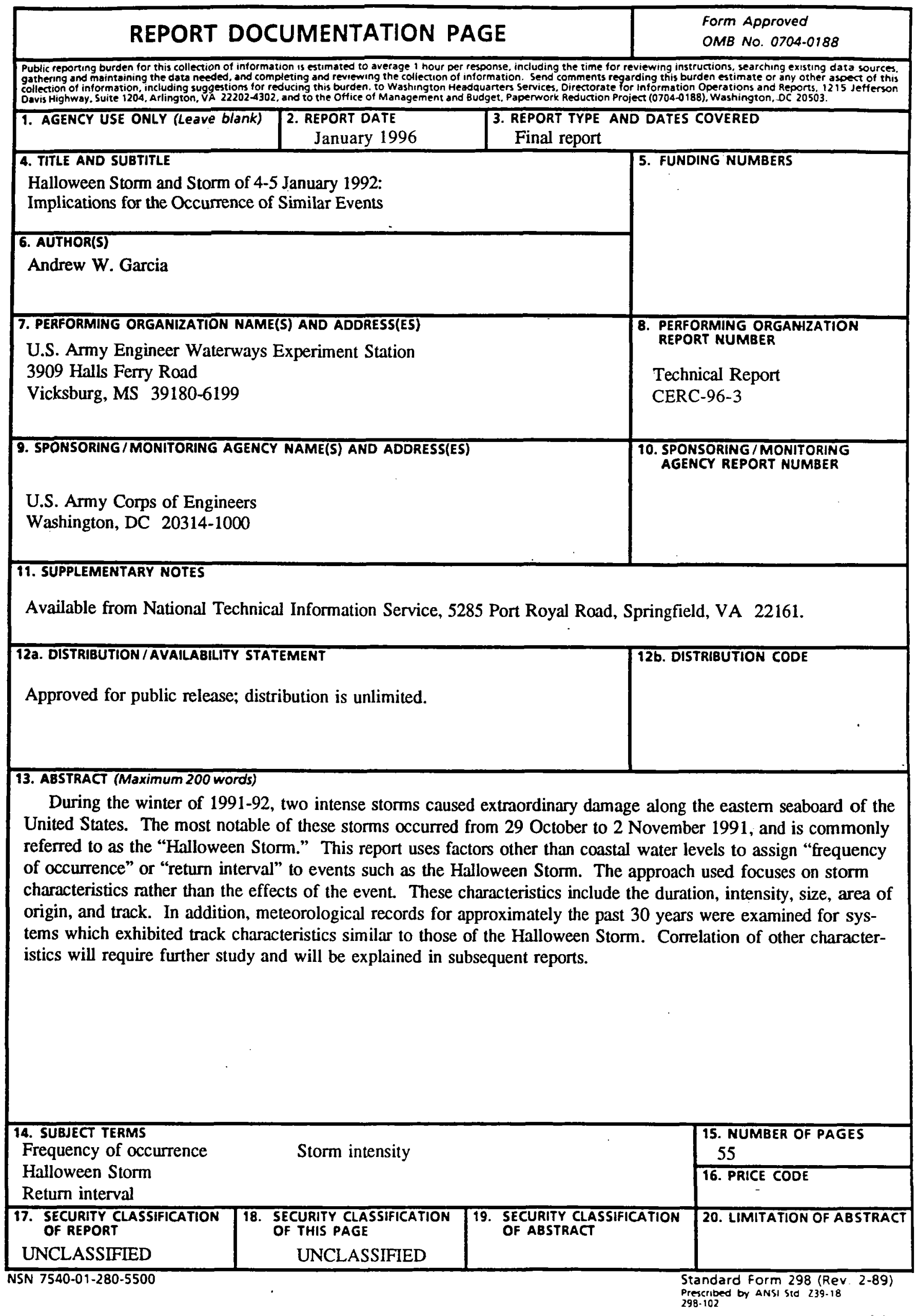

